Nevada

Environmental

Restoration

Project

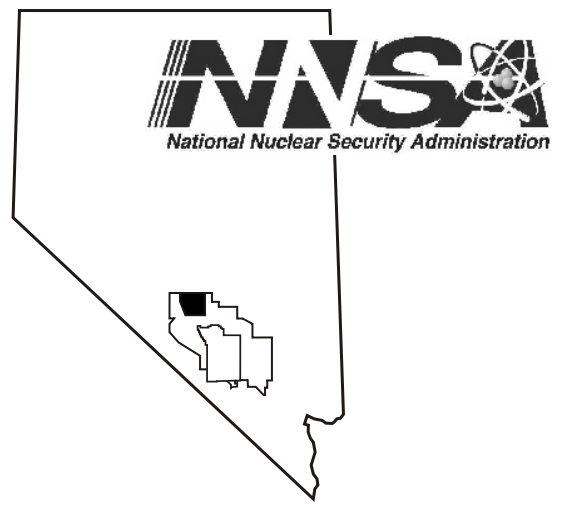

Streamlined Approach for

Environmental Restoration Plan

For Corrective Action Unit 484:

Surface Debris, Waste Sites, and Burn Area, Tonopah Test Range, Nevada

Controlled Copy No.:

Revision: 0

May 2004

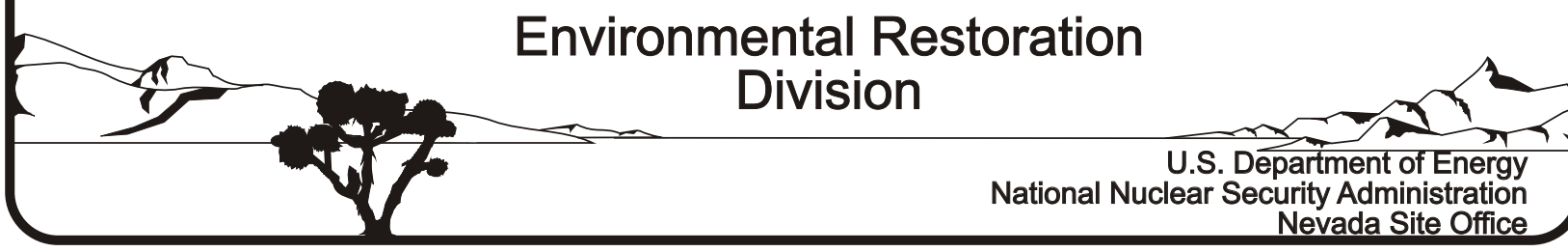




\section{DISCLAIMER}

Reference herein to any specific commercial product, process, or service by trade name, trademark, manufacturer, or otherwise, does not necessarily constitute or imply its endorsement, recommendation, or favoring by the U.S. Government or any agency thereof or its contractors or subcontractors.

This report has been reproduced directly from the best available copy.

Available for sale to the public from:

U.S. Department of Commerce

National Technical Information Service

5285 Port Royal Road

Springfield, VA 22161-0002

Telephone: (800) 553-6847

Fax: (703) 605-6900

E-mail: orders@ntis.gov

Online ordering: http://www.ntis.gov/ordering.htm

Available electronically at http://www.osti.gov/bridge.

Available for a processing fee to the U.S. Department of Energy and its contractors, in paper, from:

U.S. Department of Energy

Office of Scientific and Technical Information

P.O. Box 62

Oak Ridge, TN 37831-0062

Telephone: (865) 576-8401

Fax: (865) 576-5728

E-mail: reports@adonis.osti.gov 


\title{
STREAMLINED APPROACH FOR ENVIRONMENTAL RESTORATION PLAN FOR CORRECTIVE ACTION UNIT 484: SURFACE DEBRIS, WASTE SITES, AND BURN AREA TONOPAH TEST RANGE, NEVADA
}

\author{
Prepared for: \\ U.S. Department of Energy \\ National Nuclear Security Administration \\ Nevada Site Office \\ Under Contract No. DE-AC08-96NV11718
}

Controlled Copy No.

Revision: 0

May 2004 
THIS PAGE INTENTIONALLY LEFT BLANK 


\section{STREAMLINED APPROACH FOR ENVIRONMENTAL RESTORATION PLAN FOR CORRECTIVE ACTION UNIT 484: SURFACE DEBRIS, WASTE SITES, AND BURN AREA TONOPAH TEST RANGE, NEVADA}

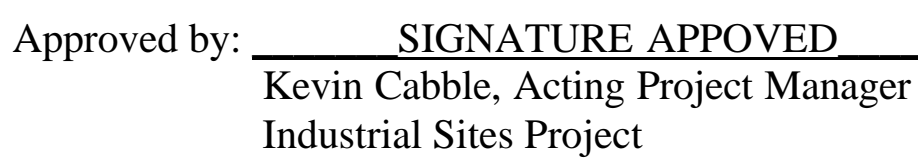

Date: $\quad[04 / 28 / 04$

Date: 
THIS PAGE INTENTIONALLY LEFT BLANK 


\section{TABLE OF CONTENTS}

ACRONYMS AND ABBREVIATIONS........................................................................ vii

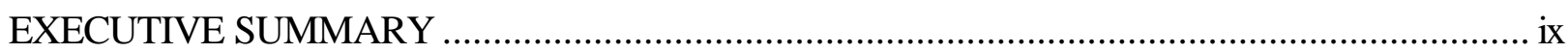

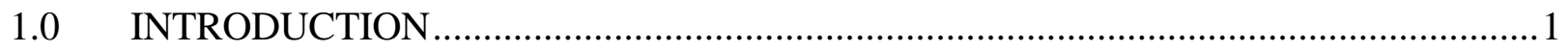

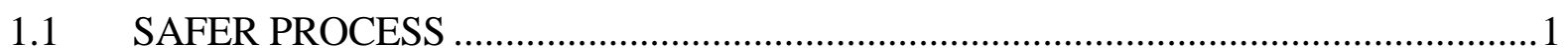

1.2 SUMMARY OF PROPOSED CORRECTIVE ACTIONS …....................................

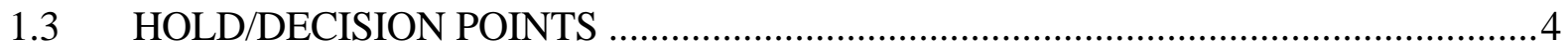

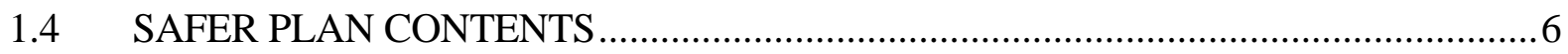

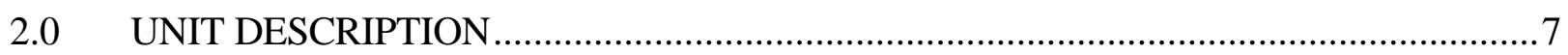

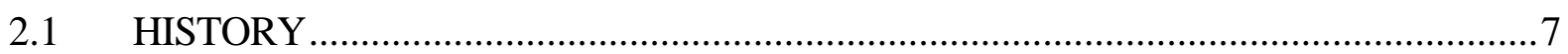

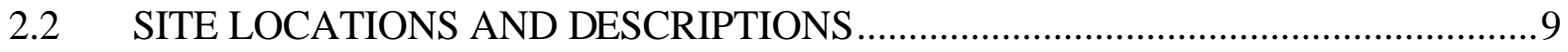

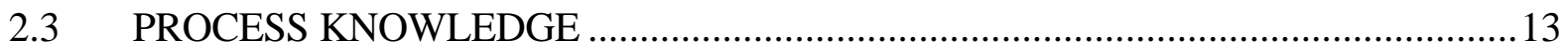

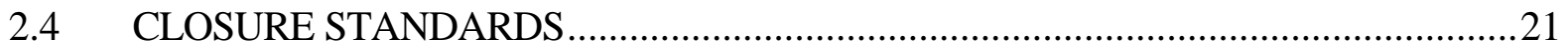

3.0 FIELD ACTIVITIES AND CLOSURE OBJECTIVES ...........................................2

3.1 CONTAMINANTS OF POTENTIAL CONCERN …...........................................25

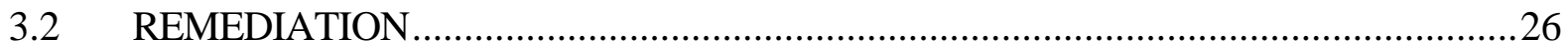

3.2.1.1 Surface Detonation Debris Sites Survey and Sampling Activities........................27

3.2.1.2 Surface Detonation Areas Remediation.............................................................29

3.2.1.3 Closure by No Further Action.................................................................. 30

3.2.2.1 Surface-Shallow Subsurface Debris Areas Investigation.....................................30

3.2.2.2 Surface-Shallow Subsurface Debris Area Remediation...................................... 31

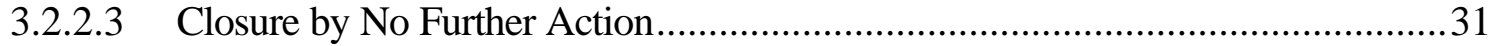

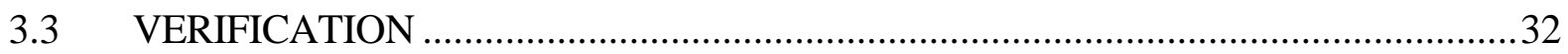

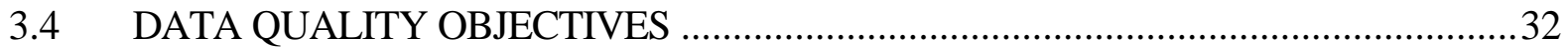

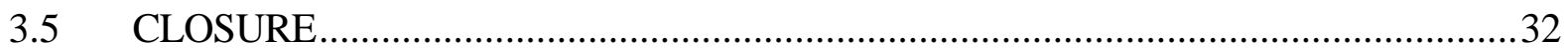

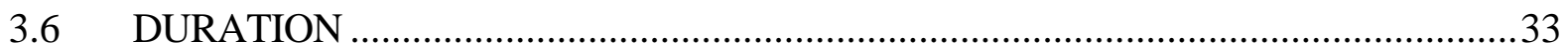

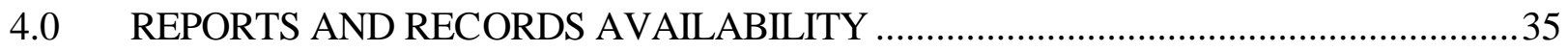

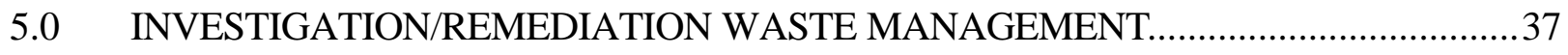

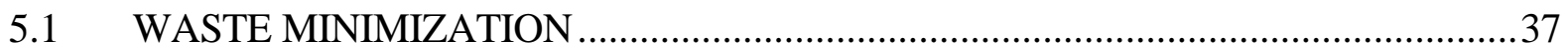

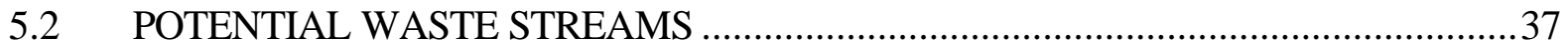

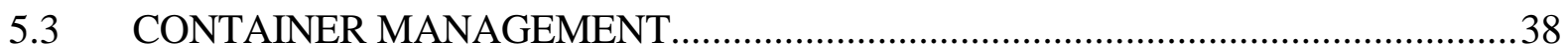




\title{
TABLE OF CONTENTS (continued)
}

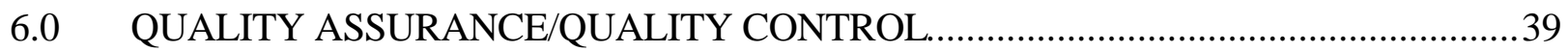 \\ 6.1 PROPOSED FIELD SAMPLE COLLECTION ACTIVITIES.......................................39 \\ 6.2 PROPOSED LABORATORY/ANALYTICAL DATA QUALITY INDICATORS .......39 \\ 7.0 REFERENCES

\section{FIGURES}

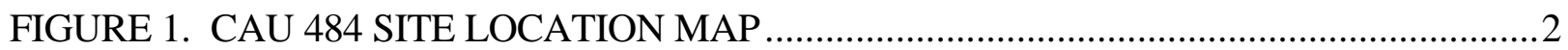

FIGURE 2. CAU 484 PROPOSED SAFER CLOSURE PROCESS ………..............................5

FIGURE 3. CAS RG-52-007 TAML, DAVIS GUN PENETRATOR TEST .................................10

FIGURE 4. CAS TA-52-001-TANL, NEDS DETONATION AREA ………….........................11

FIGURE 5. CAS TA-52-004-TAAL, METAL PARTICLE DISPERSION TEST...........................12

FIGURE 6. CAS TA-52-006-TAPL, DEPLETED URANIUM SITE ..........................................14

FIGURE 7. CAS TA-52-006-TAPL, DEPLETED URANIUM SITE ..........................................15

FIGURE 8 CAS TA-54-001-TANL, CONTAINMENT TANK AND STEEL STRUCTURE ....16

FIGURE 9. POTENTIAL DAVIS GUN TEST LOCATION, ANTELOPE LAKE.......................18

FIGURE 10. CAU 484 SAFER FIELDWORK PROPOSED SCHEDULE ...................................34

\section{TABLES}

TABLE 1. WASTE/CONTAMINANTS OF POTENTIAL CONCERN .....................................26

TABLE 2. POTENTIAL WASTE STREAMS BY CAS AT CAU 484 ……..................................

TABLE 3. LABORATORY/ANALYTICAL DATA QUALITY .................................................41

\section{APPENDICES}

APPENDIX A1 - DATA QUALITY OBJECTIVES FOR CAU 484

APPENDIX A2 - PROJECT ORGANIZATION

DISTRIBUTION LIST 


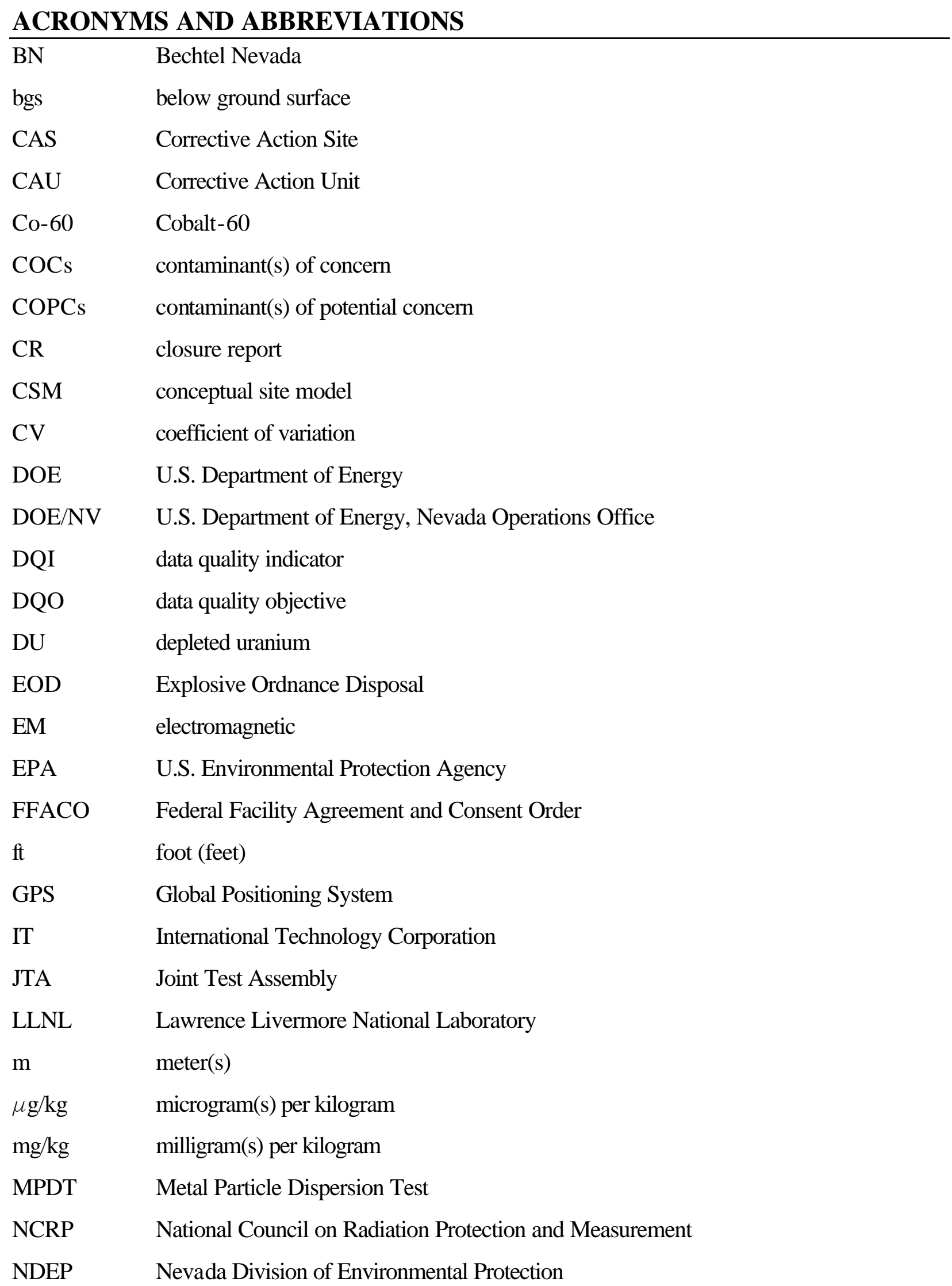




\section{ACRONYMS AND ABBREVIATIONS (continued)}

NEDS Nonviolent Explosive Destruct System

NNSA/NSO U.S. Department of Energy, National Nuclear Security Administration Nevada Site Office

NNSA/NV U.S. Department of Energy, National Nuclear Security Administration Nevada Operations Office

NTTR Nevada Testing and Training Range

NTS Nevada Test Site

$\mathrm{pCi} / \mathrm{g} \quad$ picoCuries per gram

PPE personal protective equipment

PRG preliminary remediation goals

QA quality assurance

QC quality control

RDGPS real-time differential global positioning system

REDAR Radiation and Environmental Data Acquisition and Recorder

RSL Remote Sensing Laboratory

SAFER Streamlined Approach for Environmental Restoration

SNL Sandia National Laboratories

SNM special nuclear materials

TTR Tonopah Test Range

UXO unexploded ordnance 


\section{EXECUTIVE SUMMARY}

This Streamlined Approach for Environmental Restoration plan details the activities necessary to close Corrective Action Unit (CAU) 484: Surface Debris, Waste Sites, and Burn Area (TTR). CAU 484 consists of sites located at the Tonopah Test Range, Nevada, and is currently listed in Appendix III of the Federal Facility Agreement and Consent Order. CAU 484 consists of the following six Corrective Action Sites:

- CAS RG-52-007-TAML, Davis Gun Penetrator Test

- CAS TA-52-001-TANL, NEDS Detonation Area

- CAS TA-52-004-TAAL, Metal Particle Dispersion Test

- CAS TA-52-005-TAAL, Joint Test Assembly DU Sites

- CAS TA-52-006-TAPL, Depleted Uranium Site, and

- CAS TA-54-001-TANL, Containment Tank and Steel Structure

CAU 484 closure activities will be based on the results of historical document reviews, site visits, process knowledge, results of geophysical, radiological, and multispectral surveys, aerial photography, and waste characterization sampling. If no contaminants of potential concern (COPCs) are found at a Corrective Action Site (CAS) and no waste is present, the site will be closed by taking no further action. If contaminants of concern (COCs) are determined to be present at a CAS and it is technically feasible, the materials will be removed and disposed, and the site will be clean-closed.

Based on existing information and process knowledge, COPCs and waste at the CASs in CAU 484 are limited to DU, beryllium, and inert debris. An unconfirmed sealed cobalt-60 (Co-60) source may also be present at one location. Field activities are planned to confirm the existing site information and assess the previously completed cleanup activities at locations where detonation experiments were conducted. Depleted uranium contamination and cleanup will be evaluated using field survey methods. Beryllium will be evaluated using sampling and analytical methods. Depleted uranium cleanup assumes a "hot spot" removal and will be based on the minimum detectable quantity of the field survey instrument used. Soil samples may also be collected to confirm DU concentrations and for cleanup verification. Beryllium analytical results will be compared to Environmental Protection Agency Region 9 Preliminary Remediation Goals to determine cleanup requirements. Depleted uranium analytical results will be compared to the standards presented in the National Council on Radiation Protection and Measurement (NCRP) Report No. 129.

The corrective action investigation and closure activities have been planned to incorporate data collection and hold points throughout the process. Hold points are designed to allow decision makers to review the existing data and decide which of the available options are most suitable. Hold points include the review of geophysical and radiological data and field observations for selection of targets for investigation and selection of corrective actions for sites containing COCs. 
SAFER PLAN - CAU 484

Section: Executive Summary

Revision: 0

Date: May 2004

THIS PAGE INTENTIONALLY LEFT BLANK 


\subsection{INTRODUCTION}

This Streamlined Approach for Environmental Restoration (SAFER) plan details the closure activities for Corrective Action Unit (CAU) 484: Surface Debris, Waste Sites, and Burn Area (TTR). CAU 484 consists of six Corrective Action Sites (CASs) located at the Tonopah Test Range (TTR), Nevada (Figure 1), and is currently listed in Appendix III of the Federal Facility Agreement and Consent Order (FFACO, 1996). CAU 484 consists of the following six CASs:

- CAS RG-52-007-TAML, Davis Gun Penetrator Test

- CAS TA-52-001-TANL, NEDS Detonation Area

- CAS TA-52-004-TAAL, Metal Particle Dispersion Test

- CAS TA-52-005-TAAL, Joint Test Assembly DU Sites

- CAS TA-52-006-TAPL, Depleted Uranium Site, and

- CAS TA-54-001-TANL, Containment Tank and Steel Structure

\subsection{SAFER PROCESS}

CAUs that may be closed using the SAFER process have conceptual corrective actions that are clearly identified. Consequently corrective action alternatives can be chosen prior to the completion of a corrective action investigation given anticipated investigation results.

The SAFER process combines elements of the data quality objectives (DQOs) process and the observational approach to help plan and conduct corrective actions. DQOs are used to identify a problem and define the type and quality of data needed to complete the investigation phase of the process. The purpose of the investigation phase in the SAFER process is to verify the adequacy of existing information to implement the corrective actions and to support the selected corrective actions. The observational approach provides a framework for managing uncertainty and planning decision making.

Use of the SAFER process allows technical decisions to be made based on incomplete but sufficient information and the experience of the decision maker. Any uncertainties are addressed by documenting assumptions that are verified by sampling, analysis, data evaluation, and onsite observation as planned activities progress, and by contingency plans, as necessary. Remediation and closure may proceed simultaneously with site characterization as sufficient data are gathered to confirm or disprove the assumptions made in selecting the closure method. During the site closure if new information is developed that indicates the closure method should be revised, closure activities will be modified (after regulatory consent has been achieved) to implement the revised closure method.

Sufficient information is available for the CASs within CAU 484 to allow the selection of corrective action alternatives prior to the completion of the field activities. The conceptual corrective action is removal of waste/contamination and clean closure of the sites within the CAU. Field activities will be completed to collect data to validate the conceptual site model and confirm the proposed corrective action. 

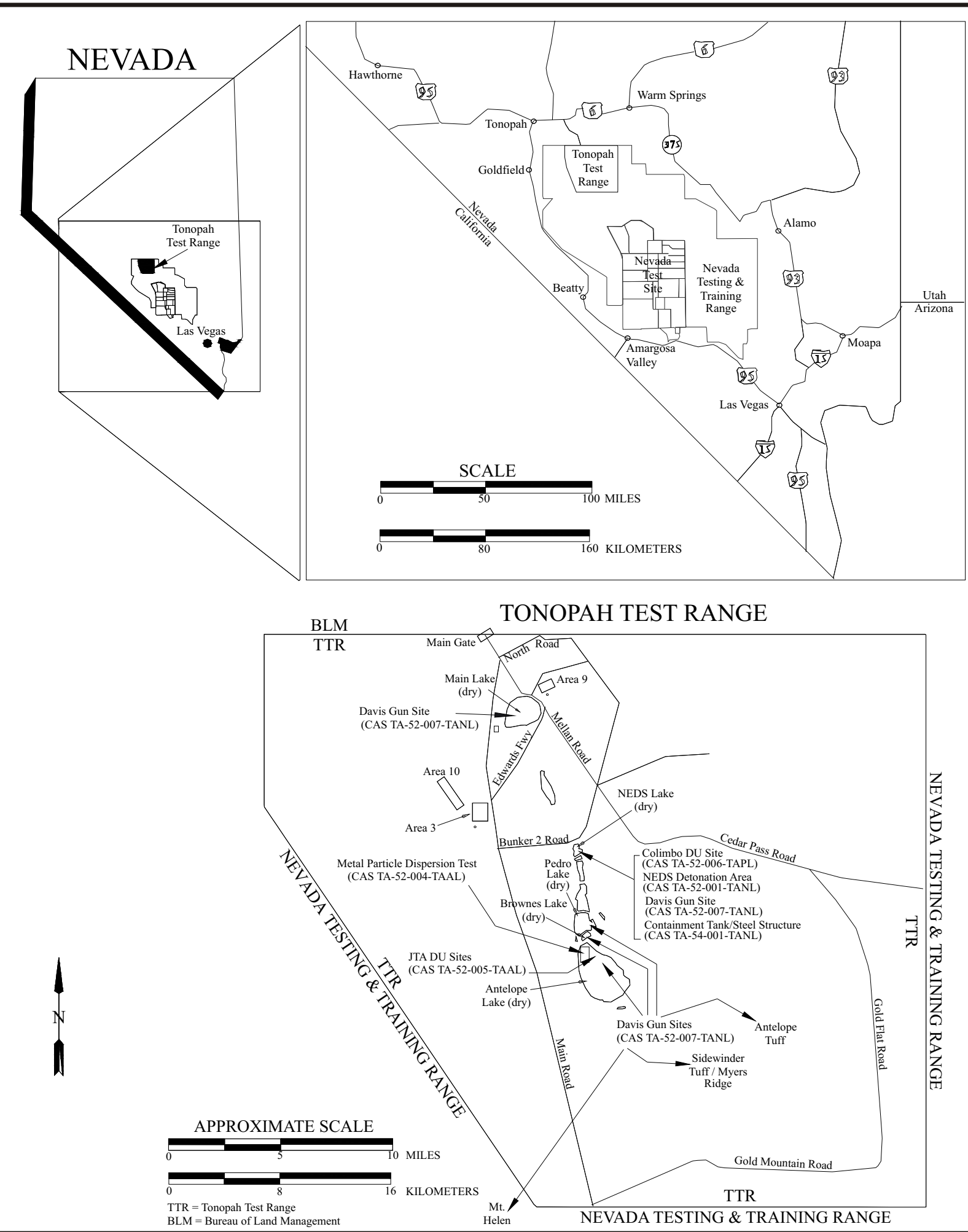

FIGURE 1

CAU 484 SITE LOCATION MAP 


\subsection{SUMMARY OF PROPOSED CORRECTIVE ACTIONS}

The presence of depleted uranium (DU) and/or waste at CASs within CAU 484 will initially be evaluated through the completion of a radiological and geophysical field survey. Waste locations will also be verified through site visits and screening with handheld radiological and electromagnetic instruments. Soil samples may also be collected to confirm DU concentrations and for cleanup verification. Corrective actions may be grouped and summarized using the three Conceptual Site Models (CSMs) developed during the project DQOs.

\section{Surface-Shallow Subsurface Debris}

If the presence of DU is verified at the two CASs within the Surface-Shallow Subsurface Debris CSM and it is feasible, the sites will be closed by removing the DU. Due to the nature of testing activities, any DU present is assumed to be in discrete pieces (e.g., DU rings at CAS TA-52-005-TAAL.) Pieces of DU and associated soil identified at these CASs will be removed, and remediation of sites impacted with DU will be verified using field-survey methods similar to DU cleanup completed at CAU 425, Area 9 Main Lake Construction Debris Disposal Area (TTR), U.S. Department of Energy National Nuclear Security Administration Nevada Site Office (NNSA/NSA, 2003). Soil samples may also be collected to confirm DU concentrations and for cleanup verification. Depleted uranium analytical results will be compared to the standards presented in the National Council on Radiation Protection and Measurement (NCRP) Report No. 129. Based on process knowledge and technology limitations, the shallow subsurface is defined as being a depth of 3 meters $(\mathrm{m})$ (10 feet [ft]) or less. The surface and shallow subsurface will be evaluated using geophysical and radiological survey methods. If a corrective action site can not be located due to unavailability of information, technology limitations, or other causes, closure of the site will proceed following the precedent established at CAU 495, Unconfirmed JTA Sites (TTR). This site was promoted to Appendix IV of the FFACO with the caveat that the site would be reopened for investigation if additional information was found in the future.

\section{Surface Detonation Debris}

If the presence of contamination over action levels is confirmed at the Surface Detonation Debris sites, and it is feasible, the corrective action will consist of removal of the contaminants and clean-closure of the CAS. The two contaminants of potential concern (COPCs) identified for Surface Detonation Debris sites are DU and beryllium. Due to the nature of the testing at the CASs within the Surface Detonation Debris CSM, if DU and beryllium are present they will be associated and will be limited to the lake bed surface. Any DU present is expected to exist as discrete fragments on the ground surface. Beryllium, if present, is expected to be associated with DU in the same general dispersal pattern. The DU fragments and any soil removed will be disposed of at an appropriate landfill based on the radiological properties of the waste. DU removal will be verified using field-survey methods (similar to DU cleanup completed at CAU 425). Beryllium corrective action investigation and closure verification will be documented through laboratory analysis of soil samples collected from the detonation areas. Soil samples may also be collected to confirm DU concentrations and for cleanup verification. The action level for beryllium is the Environmental Protection Agency (EPA) Region 9 Preliminary Remediation Goal (PRG) of 1,900 milligrams per kilogram (mg/kg) (EPA, 2002). 


\section{Non-Impacted Surface Debris}

Prior to any closure activities, the metal and wood structures will be evaluated for historical significance and radiologically screened for free release. If the structures are not found to have historical significance and free-release criteria (DOE/NV, 2000) are met, the material will be removed and disposed of as construction debris, or recycled.

\subsection{HOLD/DECISION POINTS}

During closure activities, certain conditions affecting the project schedule and budget may require decisions prior to continuing work. Primary hold points during the CAU 484 SAFER process have been identified and include the review of data for the selection of potential site locations for further investigation and the review of verification sample analytical data.

The results of geophysical and radiological surveys will be reviewed and presented to the NNSA/NSO and the Nevada Division of Environmental Protection (NDEP). Three potential outcomes are possible and each will be evaluated for further action. The potential outcomes include the following: a distinct target representing the site will be located, several potential targets will be located, or no potential targets will be identified.

Figure 2 depicts the investigation process and expected hold/decision points. If a single target is identified, the data will be reviewed and a decision will be made concerning the type and nature of data collection required to support closure of the site. If multiple potential targets are identified, a decision will be made concerning which targets are to be investigated and the nature of additional data collection required. In the event that no targets or potential targets are identified for a specific site, the alternative CSM will be evaluated for additional areas of investigation, or closure by no further action. If no further action is selected, the CAU 495, Unconfirmed JTA Sites (TTR) scenario will be implemented (with the caveat that the CAU may be closed but will be reopened if additional information is found in the future).

An additional hold/decision point occurs during the investigation when results of soil sampling and laboratory analysis for beryllium and DU screening/analytical data will be reviewed with the NNSA/NSO and the NDEP to confirm the cleanup and/or closure approach. Throughout the investigation/closure process, data will be collected, evaluated, and presented to NNSA/NSO for review and input.

In addition to the previously discussed hold/decision points, work may be temporarily suspended until the issue can be satisfactorily resolved if any of the following unexpected conditions occur:

- Conditions outside the scope of work are encountered such as large amounts of unexploded ordnance;

- Radiological screening yields results which require an upgrade in procedures to continue survey work in specific areas;

- Elevated beryllium analytical results from soil samples are found; 


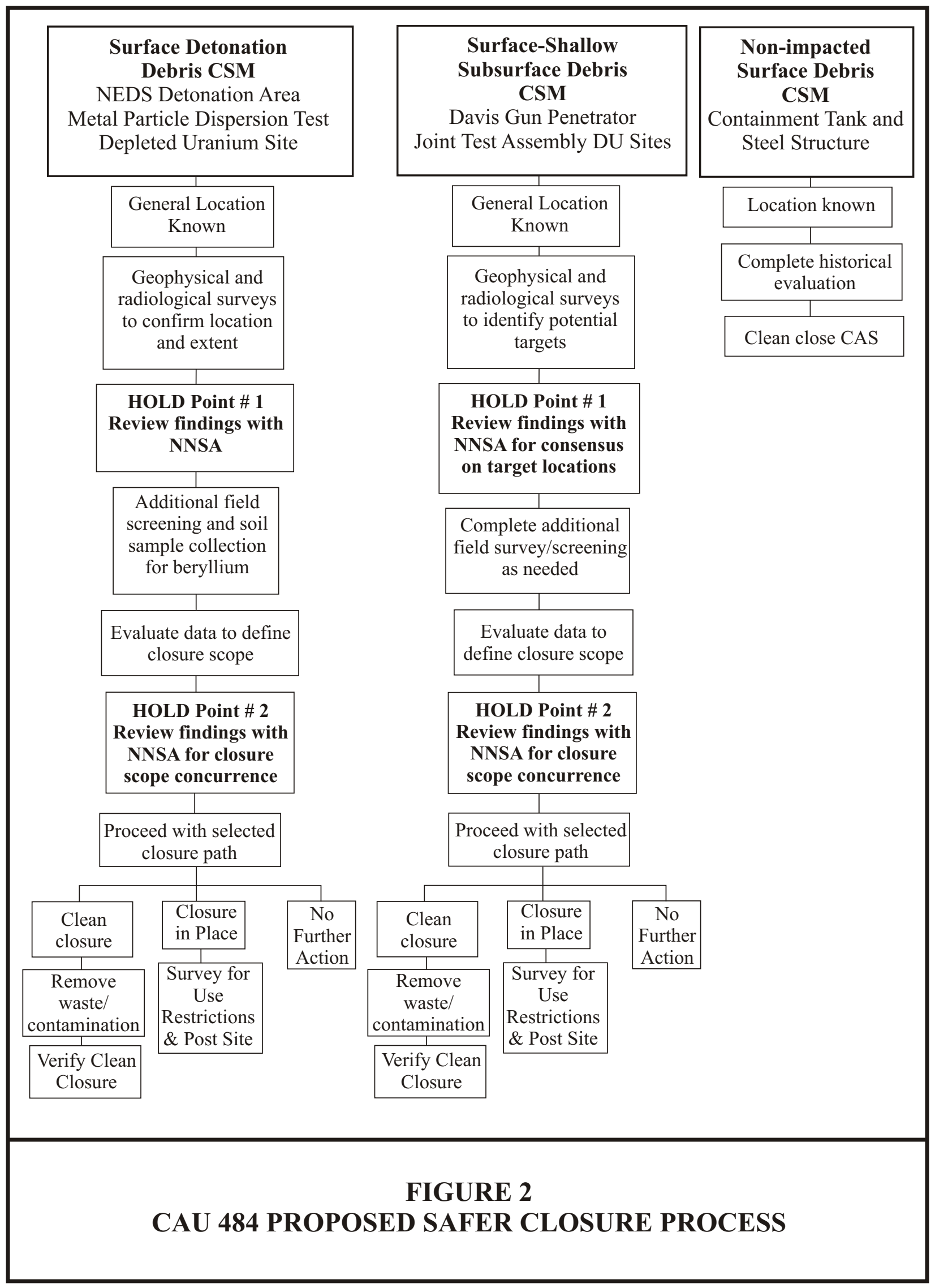


- Elevated levels of additional COPCs are found that were not originally identified as being present at the sites;

- Unexpected conditions including waste and/or contamination are encountered; Out-of-scope work activities are required due to the detection of other Contaminants of Concern (COCs) that would require re-evaluating a disposal pathway, such as with hazardous or low level waste;

- Unsafe conditions or work practices posing a threat to personnel, equipment, or the environment, not originally documented in the Site Specific Health and Safety Plan are encountered; or

- Other technical factors are encountered that require the preparation of a Record of Technical Change to the approved SAFER Plan.

\subsection{SAFER PLAN CONTENTS}

This SAFER Work Plan has been developed to support the closure of CAU 484 according to the required FFACO format, including the following content by section:

- Section 1.0 - Introduction

- Section 2.0 - Unit Description

- Section 3.0 - Field Activities and Closure Objectives

- Section 4.0 - Reports and Records Availability

- Section 5.0 - Investigation/Remediation Waste Management

- Section 6.0 - Quality Assurance/Quality Control

- Section 7.0 - References

- Appendix A1 - Data Quality Objectives

- Appendix A2 - Project Organization

- Distribution List

This SAFER plan was developed using guidance provided from the following documents:

- Federal Facility Agreement and Consent Order (FFACO, 1996).

- Industrial Sites Quality Assurance Project Plan, (U.S. Department of Energy National Nuclear Security Administration, Nevada Operations Office [NNSA/NV], 2002). 


\subsection{UNIT DESCRIPTION}

CAU 484 is comprised of six CASs located at the TTR, Nevada (Figure 1). The physical settings for these CASs are described as follows:

The majority of TTR, including NEDS Lake, Brownes Lake, Pedro Lake, and Antelope Lake, is located in Cactus Flat. Cactus Flat is an intermontane basin, typical of the Basin and Range Physiographic Province, surrounded by the Cactus Range to the southwest, the northern portion of Kawich Range to the east, and to the north. Cactus Flat is made up of Quarternary-aged alluvium eroded from the surrounding volcanic highlands. The alluvium can be divided into local landslide and talus, fan alluvium, valley-filled alluvium, and lake and shoreline deposits; each division differs in grain size, locality, and/or degree of compaction and cementation (United States Geological Survey, 1971).

\section{$2.1 \quad$ HISTORY}

\subsubsection{CAS RG-52-007-TAML, Davis Gun Penetrator Test}

The Davis Gun is a recoilless rifle used by Sandia National Laboratories to fire artillery projectiles into soil, rock, and concrete targets. According to information collected previously, the penetrators used at TTR were usually inert with the occasional use of DU as ballast. According to background documentation, Davis Gun tests are presumed to have taken place in several locations across the TTR during the 1960s through the 1990s. The reported locations where Davis Gun Penetrator tests were conducted include Antelope Tuff Target 1, Antelope Tuff Target 2, Myers Ridge, Sidewinder Tuff Target, Antelope Lake, Main Lake, Pedro Lake, Brownes Lake, and Mt. Helen. At least one test included a penetrator containing special nuclear material (SNM). The penetrator and SNM were recovered intact and were returned to the test customer. Historical information indicates that one penetrator was possibly lost on Antelope Lake in the late 1970s when a penetrator was reported as falling into a deep fracture that opened on Antelope Lake during heavy rain after a Davis Gun test was conducted. The penetrator could not be subsequently located. It is unknown if the lost penetrator contained DU or if details of the event including location are accurate.

Release of DU is not a likely scenario at Davis Gun test locations, as there is evidence to suggest that penetrators were recovered completely intact. The purpose of Davis Gun tests was to evaluate delivery system packages and a primary goal of the experiments was to recover the test components; therefore it is highly unlikely that test components were left at the sites where the experiments were conducted. An unrecoverable penetrator would be considered a test failure. No failures for Davis Gun tests have been reported other than the potential loss of one test package down a fracture.

\subsubsection{CAS TA-52-001-TANL, NEDS Detonation Area}

The NEDS (Nonviolent Explosive Destruct System) Detonation Area is a test site located on the northern half of NEDS Lake and is identified within the FFACO as DU Surface Debris. The tests were performed in 1974 and involved exploding mock nuclear warheads using high 
explosive to test containment. DU and/or beryllium were used as components within the mock warheads. Although the area was cleaned and the majority of debris was recovered after the tests, the possibility remains that residual DU and/or beryllium may remain on the playa surface in the area of the detonations.

\subsubsection{CAS TA-52-004-TAAL, Metal Particle Dispersion Test}

The Metal Particle Dispersion Test is the site of a 1987 experiment in which a W-82 mock nuclear artillery shell was detonated with high explosive to test dispersal patterns. DU and/or beryllium were used to simulate the dispersal of system components and radioactive materials. The location of the test is documented and a recovery operation took place after the test to map the dispersion of the test article fragments; however, cleanup verification was not documented. A soil berm was also constructed around the area of the test to prevent flooding of the test area. Residual radiological materials may remain within the bermed area depending on the thoroughness of the cleanup completed in1987.

\subsubsection{CAS TA-52-005-TAAL, Joint Test Assembly DU Sites}

The Joint Test Assembly (JTA) experiments were conducted in 1987 and involved firing four W-33 mock nuclear artillery shells from a 155-millimeter howitzer. The projectiles were fired from Area 9 toward Antelope Lake. The artillery rounds reportedly contained DU rings for additional reaction mass. Interviews of project personnel indicate that up to three of the rings were never recovered despite a 5-square kilometer (2-square mile) search of the impact area on the northern portion of Antelope Lake. For this reason, DU associated with the JTA experiments may be present on the surface or shallow subsurface of the northern portion of Antelope Lake.

\subsubsection{CAS TA-52-006-TAPL, Depleted Uranium Site}

The Colimbo test was conducted in 1985 and consisted of the detonation of a fully configured W-81 cruise missile above the surface of NEDS Lake. Recovery and cleanup operations were conducted to remove components and debris related to the test. However, there may be residual DU and/or beryllium as well as an unconfirmed sealed Co-60 radiological source remaining on the playa surface near the site of detonation. The sealed Co- 60 source was used to assist in locating portions of the test article. The location of the detonation is well documented by a survey monument on the ground surface below the detonation.

\subsubsection{CAS TA-54-001-TANL, Containment Tank and Steel Structure}

CAS TA-54-001-TANL was originally described as a location used for burning rocket fuel. The CAU is incorrectly described as containing a burn area because the tank was thought to have been used for burning rocket fuel. However, burning of rocket fuel was determined not to have occurred at this location and the CAS name was changed to "Containment Tank and Steel Structure." The "containment tank" was actually designed to be used as a shelter by personnel during some type of testing activity. The use of the steel structure is unknown. However, both the containment tank and steel structure were used at a different location at TTR and were subsequently moved to their present location. It is unknown if the tank and steel structure are related to the NEDS test. 


\subsection{SITE LOCATIONS AND DESCRIPTIONS}

\subsubsection{CAS RG-52-007-TAML, Davis Gun Penetrator Test}

CAS RG-52-007-TAML, Davis Gun Penetrator Test, consists of up to nine locations at TTR and the Nevada Testing and Training Range (NTTR) and is identified within the FFACO as DU Surface Debris (FFACO, 1996). The locations where Davis Gun Penetrator tests may have been conducted include Antelope Tuff Target 1, Antelope Tuff Target 2, Myers Ridge, Sidewinder Tuff Target, Antelope Lake, Main Lake, Pedro Lake, Brownes Lake, and Mt. Helen (Figure 3).

Areas where Davis Gun tests occurred are generally identified on the lakebeds by the remains of soil berms that were constructed around the test locations to protect the post-test recovery operations from flooding. Several areas of apparent berm remnants possibly related to the Davis Gun tests are visible on aerial photography and multispectral survey data collected in 2003.

Locations where Davis Gun tests were conducted in areas of hard rock (e.g., Antelope Tuff, Myers Ridge) are generally identified by evidence of entry holes and excavation operations that were undertaken to recover the test packages.

\subsubsection{CAS TA-52-001-TANL, NEDS Detonation Area}

The NEDS Detonation Area (Figure 4) is located on the northern half of NEDS Lake and is identified within the FFACO as DU Surface Debris (FFACO, 1996). The general location of the tests is known and has been determined to be restricted to the northeastern quadrant of NEDS Lake based on process knowledge, historical information, and site visits.

\subsubsection{CAS TA-52-004-TAAL, Metal Particle Dispersion Test}

The Metal Particle Dispersion Test (MPDT) is located within the northwest corner of Antelope Lake (Figure 5) and is identified within the FFACO as DU Surface Debris (FFACO, 1996). The site is characterized by a soil berm with dimensions of approximately 610 by $914 \mathrm{~m} \mathrm{(2,000} \mathrm{by} \mathrm{3,000} \mathrm{ft).} \mathrm{The}$ soil berm was constructed immediately following the test to protect the recovery operations from flooding. Historical information indicates that the single package was detonated on the ground surface and a thorough recovery and mapping of the dispersal pattern was performed by test personnel. 


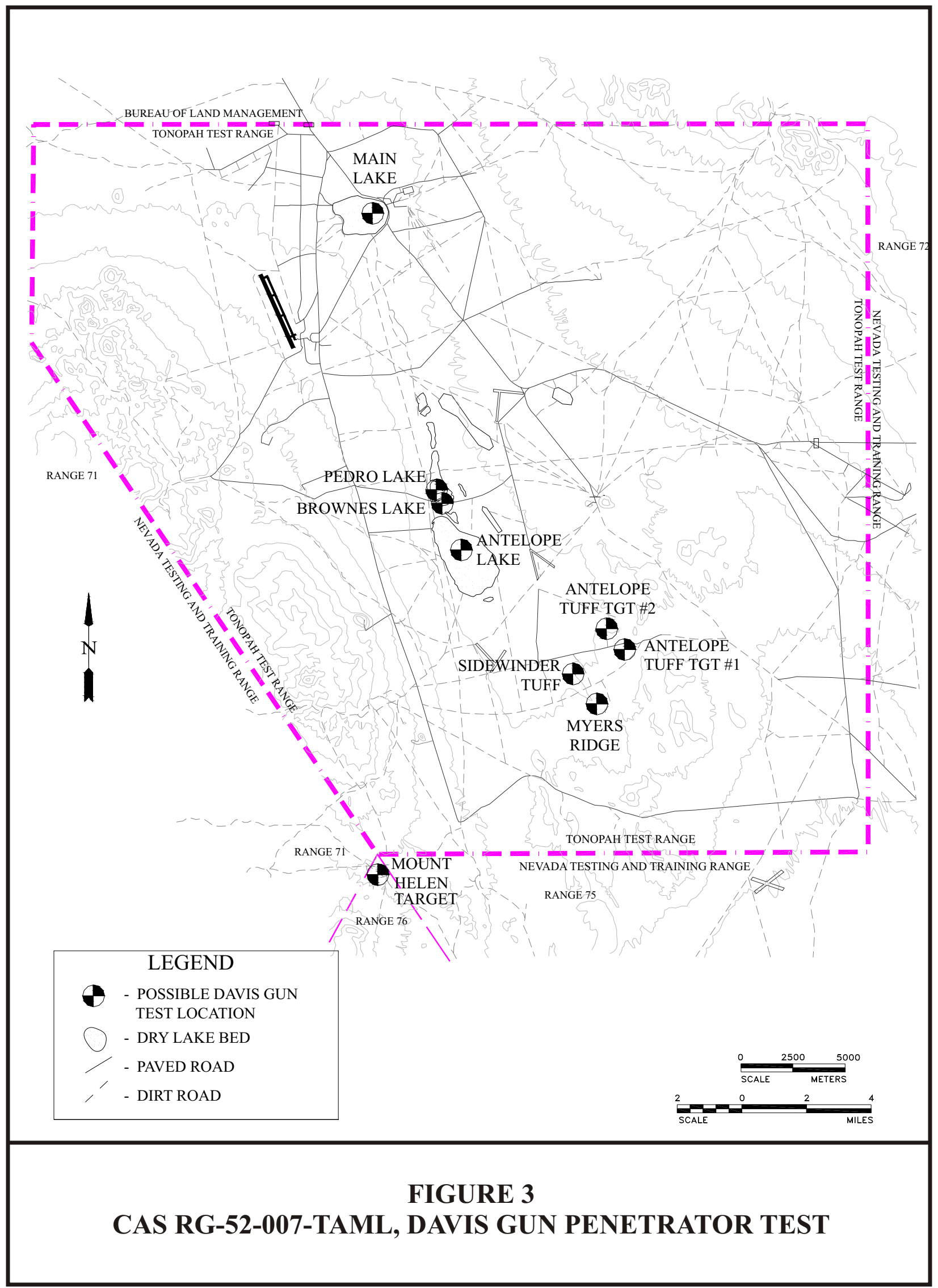




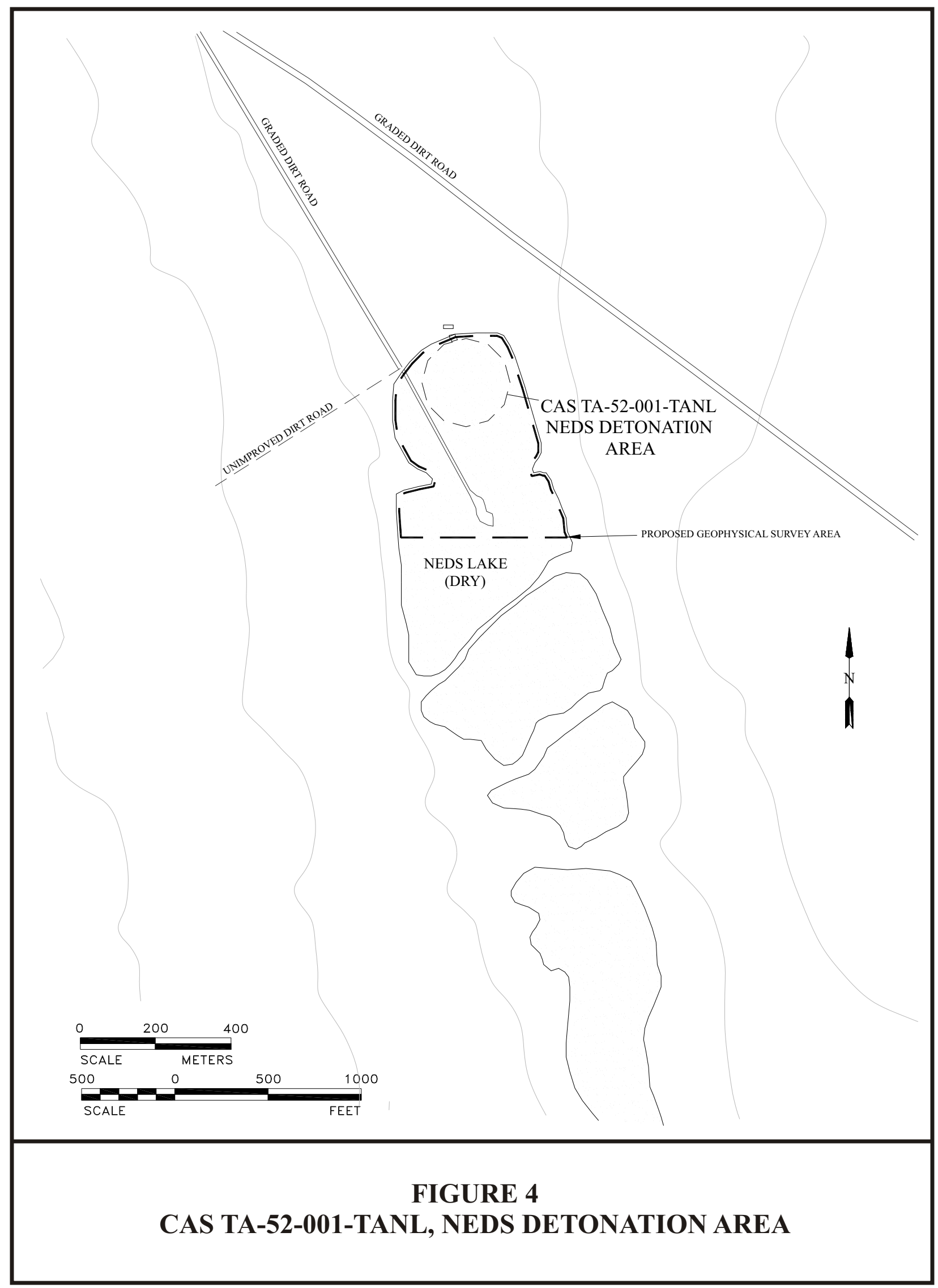




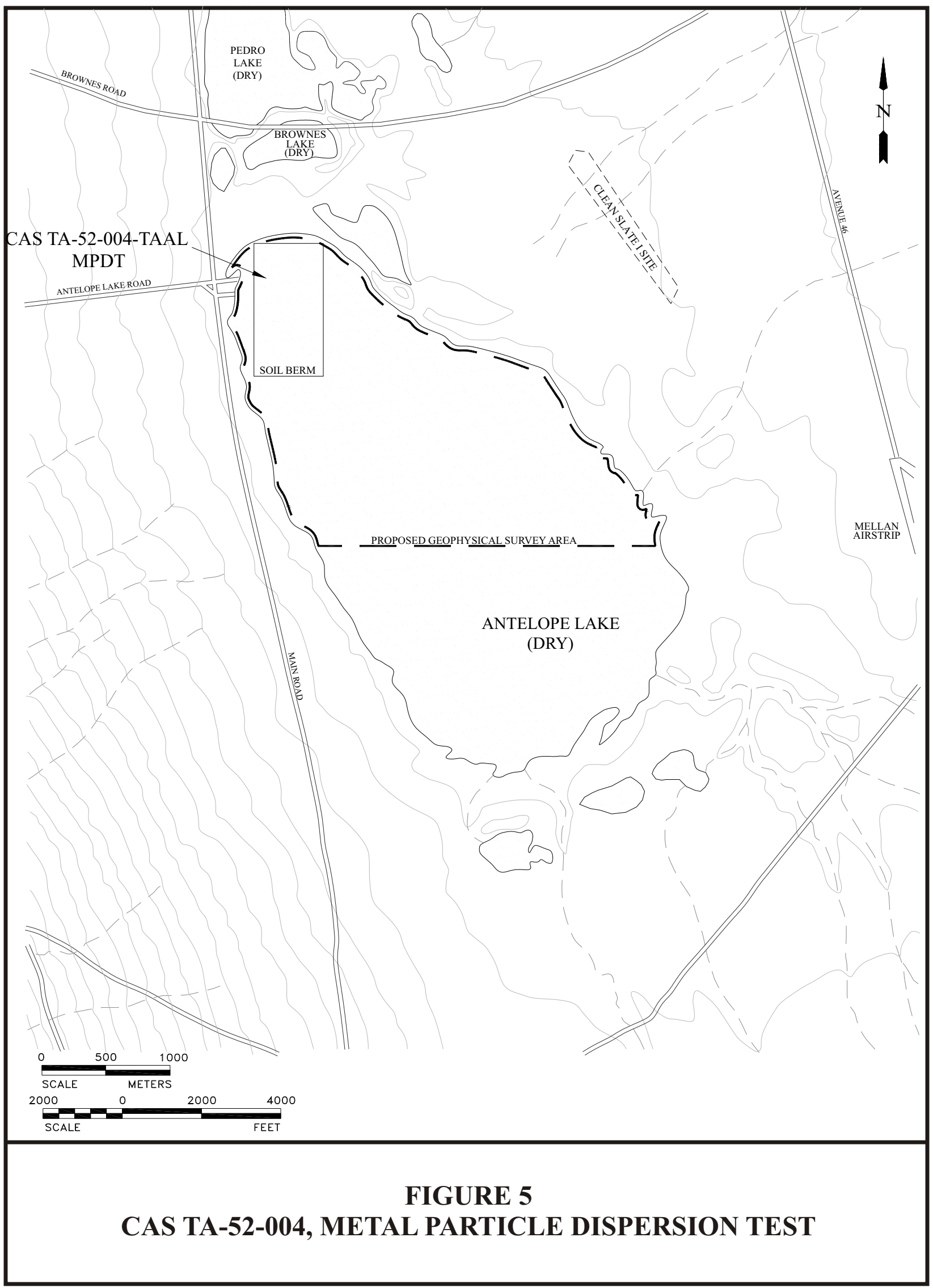




\subsubsection{CAS TA-52-005-TAAL, Joint Test Assembly DU Sites}

The Joint Test Assembly (JTA) DU Sites are located within the northern portion of Antelope Lake (Figure 6) and are identified within the FFACO as DU Surface Debris (FFACO, 1996). The exact location of the three DU rings is not known. Documents indicate that a five-square kilometer area (two square mile) was searched unsuccessfully. The area where the DU rings were reported lost is located within the search area for other CASs on Antelope Lake.

\subsubsection{CAS TA-52-006-TAPL, Depleted Uranium Site}

The Depleted Uranium Site is located on the northeast portion of NEDS Lake (Figure 7) and was the result of the Colimbo Test detonation. The CAS is identified within the FFACO as DU Surface Debris (FFACO, 1996). The Colimbo Test detonation was an aerial detonation of a test package and the location directly below the detonation is marked with a brass survey monument. The dispersal pattern was mapped by test personnel during recovery activities to remove the detonation debris. A sealed Co-60 radiological source may also remain at the site.

\subsubsection{CAS TA-54-001-TANL, Containment Tank and Steel Structure}

Several large pieces of non-impacted waste/debris are located at the north end of NEDS Lake (Figure 8). Although the origin of the structures is unknown, they may have been used during the NEDS tests or other activities on NEDS Lake. The tank and structure have been previously evaluated and determined not to be contaminated, therefore they are considered non-impacted housekeeping waste/debris and will be cleaned up accordingly.

\subsection{PROCESS KNOWLEDGE}

Although historical information about the CASs in CAU 484 is limited, these CASs are related to testing activities conducted at the TTR. Based on process knowledge, the CASs within CAU 484 may be divided into sites with surface detonation debris, sites with surface and/or shallow subsurface debris, and one site with non-impacted surface debris. An additional records search of the archives at Sandia National Laboratory in Livermore, California and Albuquerque, New Mexico will be completed prior to planning the corrective action fieldwork.

\subsubsection{CAS RG-52-007-TAML, Davis Gun Penetrator Test}

Process knowledge for the Davis Gun sites includes review of documentation, interviews with TTR personnel, site reconnaissance, and review of aerial photography and multispectral imagery. Project documentation describes the general operation of the Davis Gun, test locations, and materials used during testing of the penetrators. However, due to the extensive testing history of the Davis Gun (early 1970s through 1991), thorough documentation of these activities has not been located. Potential locations of Davis Gun tests on dry lake beds are limited to the northern half of Antelope Lake, Brownes Lake, Pedro Lake, the northern portion of NEDS Lake, and Main Lake. Documentation of Davis Gun testing in the 1970s and early 1980s is incomplete. 


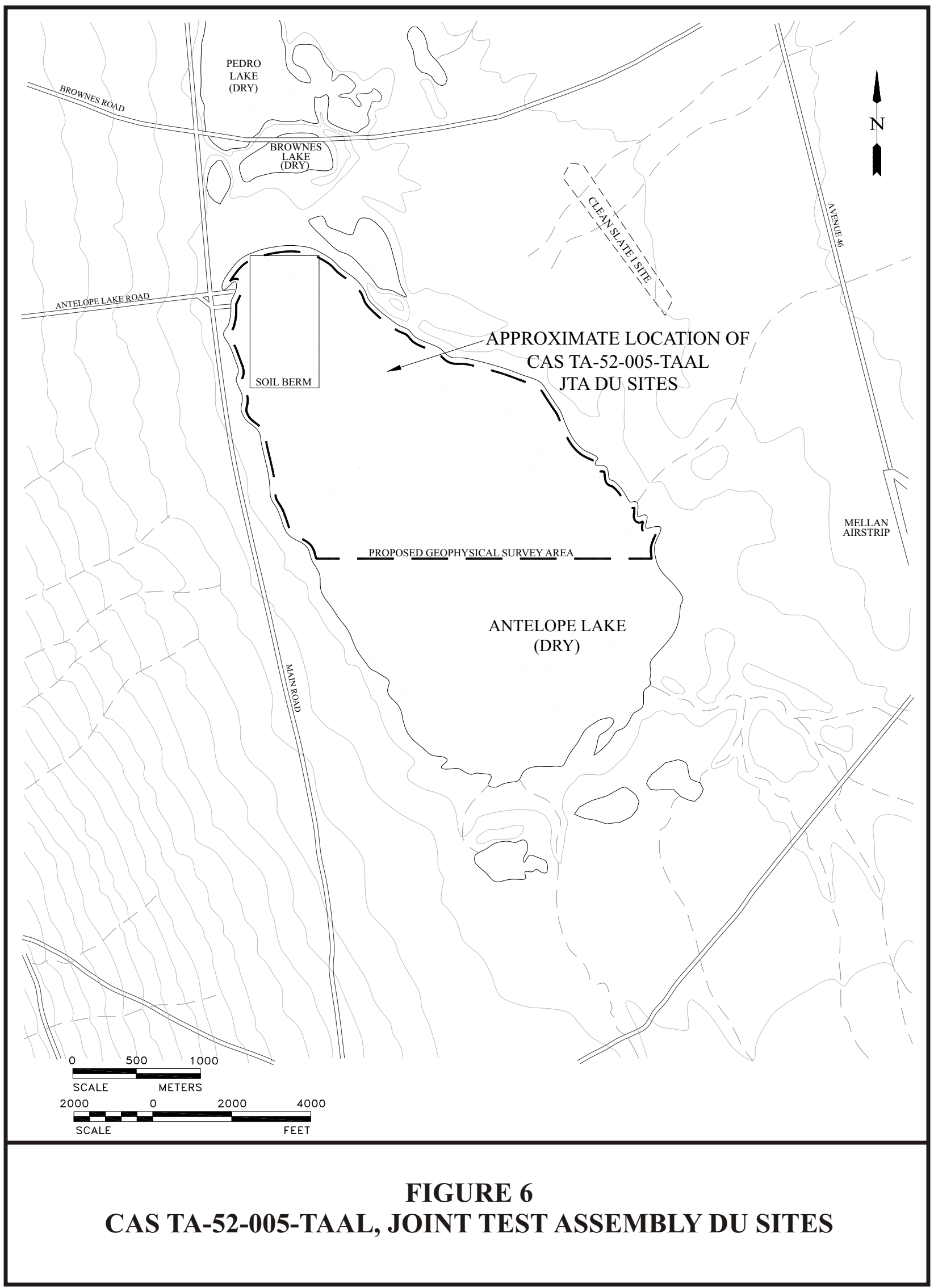




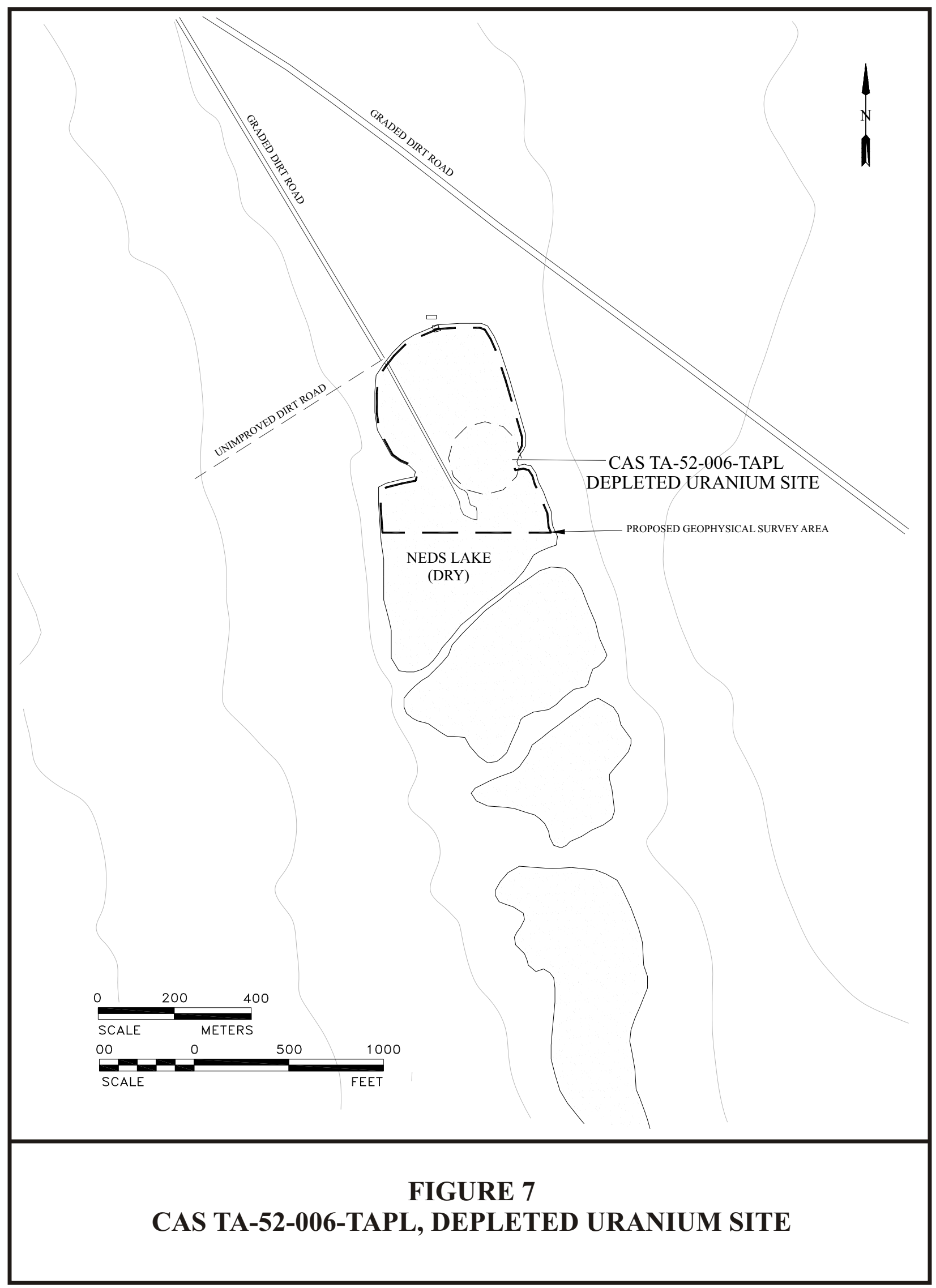




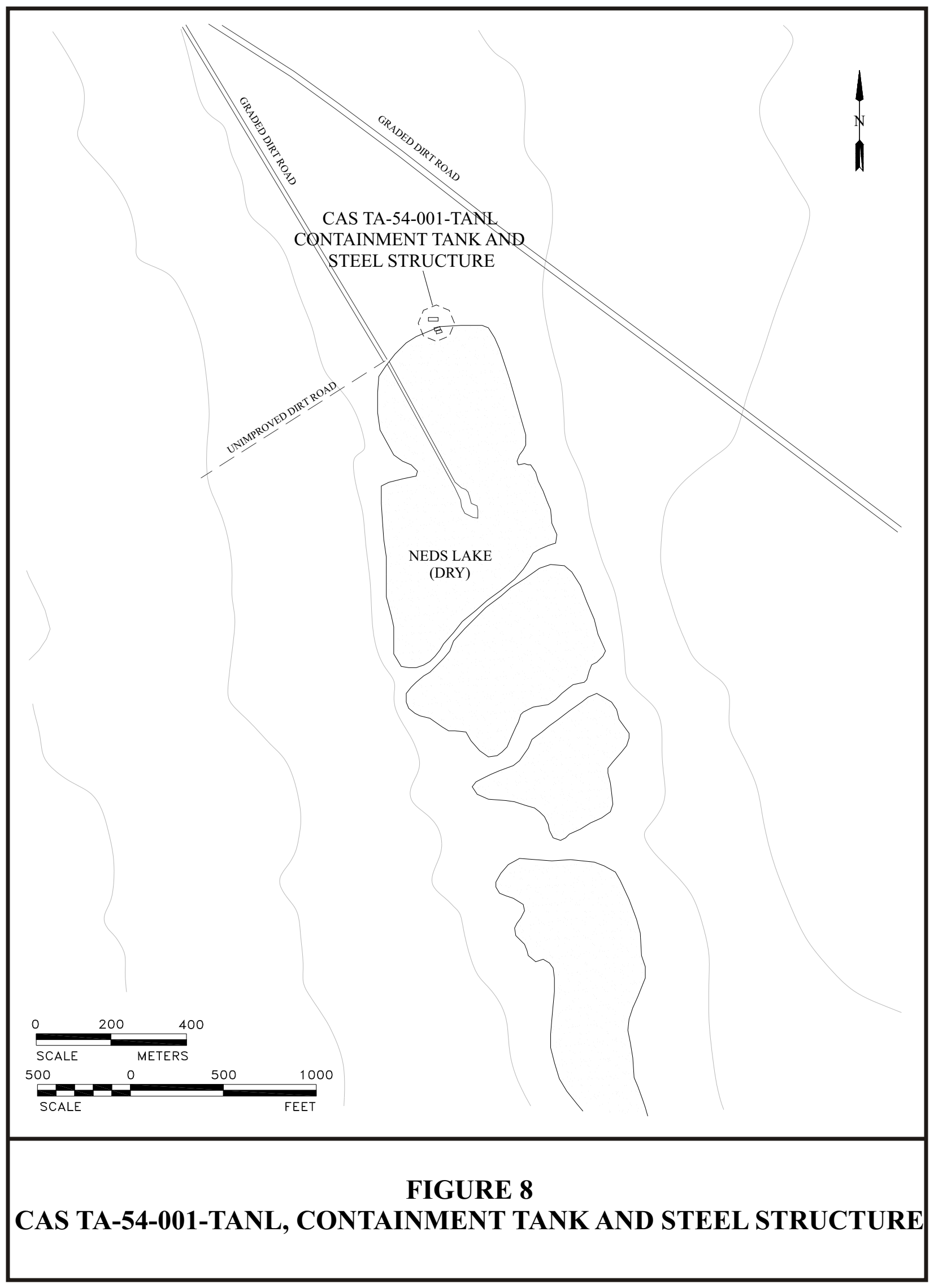


The reported locations for Davis Gun Penetrator tests include Antelope Tuff Target 1, Antelope Tuff Target 2, Myers Ridge, Sidewinder Tuff Target, Antelope Lake, Main Lake, Pedro Lake, Brownes Lake, and Mt. Helen. Documentation (International Technology Corporation [IT], 2003) states that a primary component of the Davis Gun tests was to recover the projectile, therefore lost penetrators are not likely. However, process knowledge indicates that waste and/or DU contamination may be present on the ground surface or within the shallow subsurface at test locations. Documentation indicates that penetrators were constructed of steel and often contained DU to simulate SNM and/or to add ballast during penetrator testing activities. One penetrator did contain plutonium, but the penetrator and plutonium were recovered intact and returned to the customer.

While the extensive fissure network on Antelope Lake is largely due to natural processes, one document discusses some fissures on Antelope Lake that apparently resulted from Davis Gun testing (IT, 2003). This fissuring event is the same in which a projectile was apparently lost. An interview with personnel involved with the Davis Gun testing included a discussion of a lost penetrator on Antelope Lake due to the opening of a fissure in the test area. The personnel involved with this test indicated that the penetrator was most likely inert steel and did not contain DU. A review of aerial photography and multispectral imagery indicates one likely location on Antelope Lake that correlates to the fissure story. Figure 9 depicts a possible Davis Gun test location enclosed by an earthen berm with three separate fissures radiating from the apparent test location. This area is included in the geophysical and radiological drive-over survey and will be evaluated for potential surface or subsurface DU. Some interviewees indicated that all Davis

Gun projectiles with DU were recovered intact; however some tests using a solid steel penetrator broke up during recovery operations. All of the interviewees agreed that no DU remained in the holes as a result of penetration test activities.

Site reconnaissance of the reported test locations indicates that no noticeable debris or contamination is present. Test locations on the lake beds are sometimes evident by the remnants of a soil berm, and test locations in rock are easily discernable by piles of rock debris generated during recovery operations. Aerial photography and multispectral data are useful tools in locating the potential Davis Gun test locations on the lake beds since the areas of disturbed ground are more easily observed on the images.

\subsubsection{CAS TA-52-001-TANL, NEDS Detonation Area}

Process knowledge for the NEDS site includes review of documentation, interviews with TTR personnel, site reconnaissance, and review of aerial photography/multispectral imagery. Project documentation (IT, 2003) describes the general activities and the location of the NEDS tests. The NEDS tests were conducted in 1974 on the surface of the northern portion of what is now known as NEDS Lake. The NEDS tests were conducted by SNL to aid in the design and testing of a containment system capable of containing shrapnel and debris produced by the single-point detonation of the high explosives in a nuclear weapon. Mock nuclear weapons containing DU and beryllium were used for the testing. Cleanup of debris, DU, and beryllium was completed after each test and a final comprehensive cleanup was completed to remove DU and beryllium. 


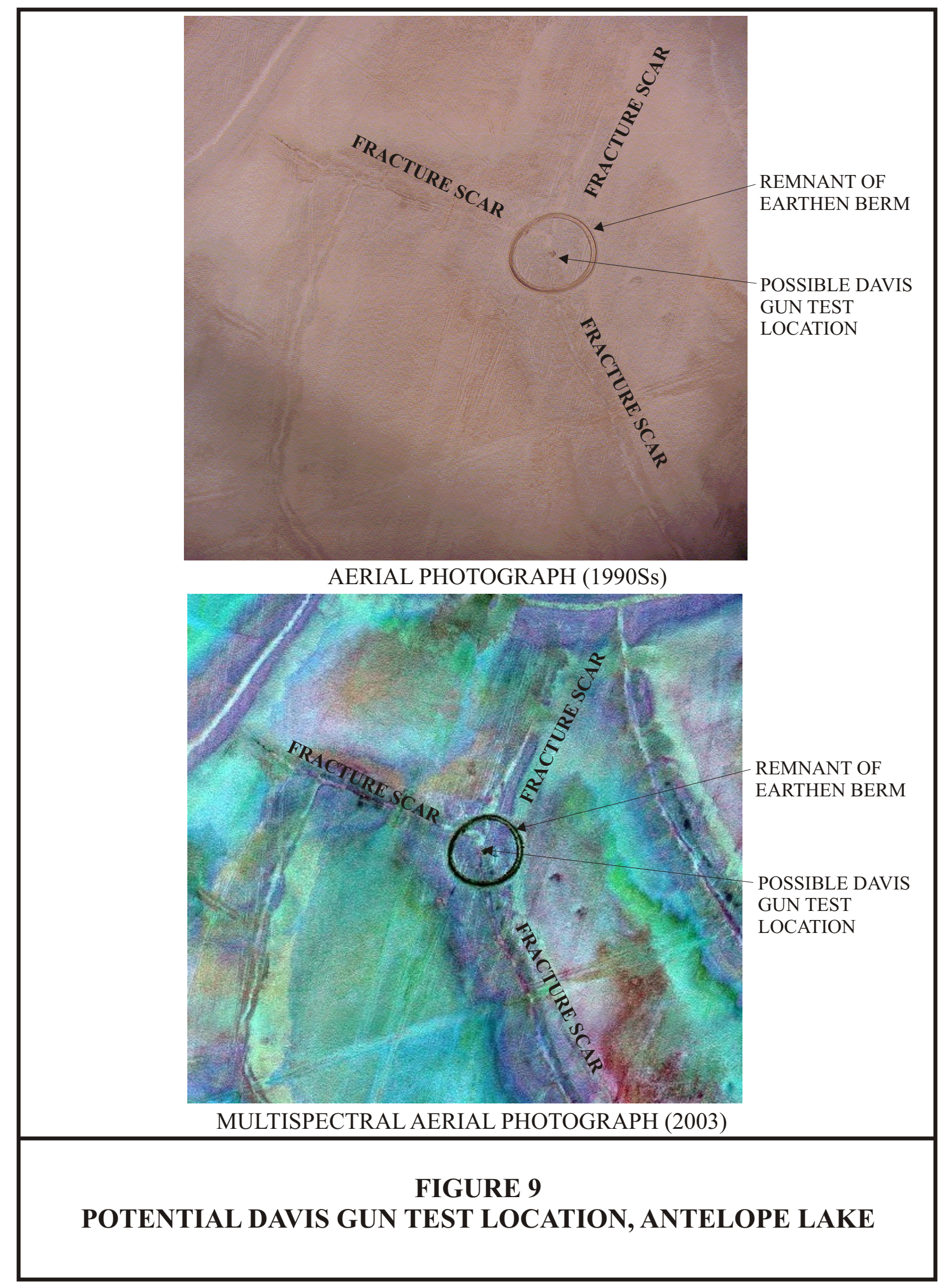


After 18 of the NEDS tests, soil samples were collected at the point of detonation and $30 \mathrm{~m}$ (100 ft) downwind. The analytical results of these samples indicated that the beryllium concentration in soil was less than the detection limit of $5 \mathrm{mg} / \mathrm{kg}$. Process knowledge indicates that waste, DU and/or beryllium may still be present on the ground surface at the test location.

It is reported that about 226 kilograms (500 pounds) of rocket fuel was burned near the NEDS test area, but was not related to the NEDS tests. Personnel interviewed concerning the NEDS site had general knowledge of the operation conducted at the site, but did not have specific information related to the NEDS tests. During site reconnaissance, a preliminary assessment site marker was located near the north end of NEDS Lake indicating the location of the NEDS test. Other than some metal debris on the ground surface, there was no discernable indication that a test had occurred at this location. Aerial photography shows the former locations of test vehicles used by TTR security personnel during training exercises but does not show any indication of testing on the north end of the lake. Historic photographs show cable runs extending from the north end of the lake to what appears to be a testing location in the center of the lake. These features are also discernable on the multispectral data. It is unknown if the activities conducted in the center portion of the lake are related to the NEDS tests.

\subsubsection{CAS TA-52-004-TAAL, Metal Particle Dispersion Test}

Process knowledge for the Metal Particle Dispersion Test includes review of documentation, interviews with TTR personnel, site reconnaissance, and review of aerial photography and multispectral imagery. Project documentation (IT, 2003) describes the purpose and scope of the test and the test results. The test was conducted on August 6, 1987, by Lawrence Livermore National Laboratory (LLNL) and consisted of the detonation of a XM785 (W-82) artillery projectile at ground surface near the northwest end of Antelope Lake. The purpose of the test was to monitor and map the dispersion of system components resulting from detonation of the high explosives contained in the unit. Project documentation indicates that the W-82 test unit detonated on the lake bed released very small amounts of DU and beryllium, and that deposition of DU and beryllium occurred near the detonation location and was far below the levels required for remedial actions. Some personnel involved in the MPDT still work at TTR and were able to provide information concerning the test and recovery activities. Since one of the goals of the test was to map the dispersion of the test unit components, a thorough cleanup of the test area was conducted and each recoverable fragment of system component was mapped and removed. Although cleanup activities were completed, there were no verification surveys completed at the site and the possibility of residual particles of DU and/or beryllium persists at the site. Process knowledge indicates that waste, DU, and/or beryllium may be present on the ground surface at the test location. A berm was constructed around an area of approximately 610 by $914 \mathrm{~m} \mathrm{(2,000} \mathrm{by} \mathrm{3,000} \mathrm{ft)}$ to protect the test location from flooding. Recovery and cleanup activities conducted and dispersal of DU and/or system components is reported to be restricted to the area enclosed by the berm. The test area is well documented and is visible on aerial photographs. An area of disturbed ground is visible on the multispectral images of the bermed area. 


\subsubsection{CAS TA-52-005-TAAL, Joint Test Assembly DU Sites}

Process knowledge for the Joint Test Assembly DU sites includes review of documentation, interviews with TTR personnel and site reconnaissance. Due to the relatively small size of the DU rings, aerial photographs and multispectral images are not useful during this phase of the investigation. Project documentation describes the general activities related to the JTA tests, and the causes of the malfunction leading to the dispersal of several DU rings. The tests involved firing W-33 mock gun rounds from Area 9 toward Antelope Lake by the U.S. Army in May 1997. Existing documentation indicates three W-33 components were lost during testing and are suspected to be buried 0.6 to $1 \mathrm{~m}$ ( 2 to $4 \mathrm{ft}$ ) beneath the surface of Antelope Lake. The W-33 malfunctioned after firing due to premature fuse function which caused anomalous scatter and dispersion of the DU rings. It is unknown if the slug contained DU. An effort was made to locate the missing components with hand-held metal detectors and gamma radiation survey instruments, but the recovery was unsuccessful due to the large survey area of approximately 5 square kilometers (2 square miles). The area in which DU rings may be located includes approximately the north half of Antelope Lake. Process knowledge indicates that DU may be present on the ground surface or shallow subsurface of Antelope Lake. Interviewees have provided conflicting opinions concerning the DU rings related to the JTA tests. Some interviewees indicated that all DU related to these test activities has been removed, whereas other interviewees indicate that the material remains on the lake surface or shallow surface. The most valuable sources of information pertaining to the reported lost DU rings is the general location on Antelope Lake and geophysical and radiological data from drive-over surveys.

\subsubsection{CAS TA-52-006-TAPL, Depleted Uranium Site}

Process knowledge for the Depleted Uranium Site includes review of documentation (IT, 2003), interviews with TTR personnel, site reconnaissance, and review of aerial photographs and multispectral images. Project documentation describes the Colimbo detonation which is the test associated with the Depleted Uranium Site. The project documentation states that Colimbo is a single explosion test that was performed in 1985. The test was conducted using a fully configured W-81 cruise missile, in which DU was used in place of SNM. The site is described as consisting of the area within a $68-\mathrm{m}(225-\mathrm{f}$ radius) of the site survey marker. One document describing the cleanup activities at the Colimbo site indicates that the DU and sealed Co-60 sources were located and removed, whereas other documentation states only one Co-60 source was located and removed. There is also inconsistency in several of the interviews conducted for this site. Altitudes of detonation are inconsistent and include heights of 304, 30, and 22 meters $(1,000,100$, and 75 feet) above the dry lake bed. Cleanup activities were completed following the detonation although the amount of DU recovered was not quantified and cleanup was not verified. The test location is well established and is marked by a brass survey monument at the point of detonation, and the dispersal and cleanup of DU, beryllium, and system components is documented. Process knowledge indicates that non-impacted waste, DU, beryllium and/or a sealed Co-60 radiological source may be present on the ground surface at the test location. 


\subsubsection{CAS TA-54-001-TANL, Containment Tank and Steel Structure}

No direct process knowledge for the Containment Tank and Steel Structure has been found. A search was conducted of pertinent documentation (IT, 2003), interviews were conducted with TTR personnel, and site visits and review of aerial photographs were completed. Existing documentation indicates that waste rocket fuel was burned in the southern portion of NEDS Lake. TTR personnel have postulated that the A-frame steel structure and tank may have been used during the rocket fuel burning process. Other personnel have indicated that the structure and tank may have been used in some activity related to the NEDS test. During a field visit to the site it was determined that the "containment tank" is actually some type of shelter for personnel and/or equipment. The tank has a door, metal retractable window, and is wired for electrical power. It is possible the tank was used as a camera bunker or personnel shielding during some testing activity. Historical aerial photographs do not show the tank or structure during the 1970s and early 1980s, but the tank and structure appear at their current location by 1988. The containment tank and steel structure are considered non-impacted surface debris and will be clean closed as a housekeeping site.

\subsection{CLOSURE STANDARDS}

Depleted uranium and beryllium are the only COPCs identified for sites within CAU 484. The clean-closure standards for the purposes of closure verification for this SAFER Plan are:

- Characterization and closure verification sample analytical results will be compared to EPA Region 9 risk-based PRG for beryllium for industrial soils (EPA, 2002b).

- The specific closure standard for DU will be the minimum detectable concentration using field survey instruments. Since DU is expected to be present in discrete pieces, survey methods similar to that used for clean closure of DU at CAU 425, Area 9 Main Lake Construction Debris Disposal Area (NNSA/NSO, 2003) will be utilized. Soil samples may also be collected to confirm DU concentrations and for cleanup verification. Analytical results will be compared to the standards presented in the National Council on Radiation Protection and Measurement (NCRP) Report No. 129 of 63 picoCuries per gram (pCi/g) Uranium 238 based on the recommended screening limits for construction, commercial, industrial land-use scenario (NCRP, 1999) scaled from 25 to 15 millirem (mrem) per year dose and the generic guidelines for residual concentration of radionuclides in U.S. Department of Energy (DOE) Order 5400.5 (DOE, 1993).

- Clean closure of CAS TA-54-001-TANL (Containment Tank and Steel Structure) will be completed by removal of the debris and verified through photo documentation.

- If the sealed Co-60 radiological source is located at CAS TA-52-006-TAPL, it will be removed and closure will be verified using radiological field screening techniques. 
SAFER PLAN - CAU 484

Section: Unit Description

Revision: 0

Date: May 2004

THIS PAGE INTENTIONALLY LEFT BLANK 


\subsection{FIELD ACTIVITIES AND CLOSURE OBJECTIVES}

This section provides the framework and rationale for characterization, removal, closure verification, site restoration, and waste disposal. The SAFER process is discussed in detail in the following subsections.

Prior to beginning the corrective action investigation and site closure fieldwork, the following activities will be completed:

- Collect aerial photography and multispectral imagery of the study areas

- Geophysical and radiological drive-over surveys of the subject lakebeds

- Review and selection of potential site targets on the lakebeds

- Additional data collection as needed to support project planning

- Development of an endangered species survey

- Preparation of National Environmental Policy Act documentation

- Preparation of a Site-Specific Health \& Safety Plan

- Cultural Resource Survey

- Preparation of an NNSA/NSO Real Estate/Operations Permit

Aerial Photography and Multispectral Survey

An aerial photography and multispectral survey was flown by the U.S. Department of Energy, National Nuclear Security Administration Remote Sensing Laboratory (RSL) in September 2003. The focus of this effort was to gather detailed photographs and multispectral data for areas where testing activities were reported to have been conducted but could not be precisely verified by site visits. The data were collected for Antelope Lake, Brownes Lake, Pedro Lake, NEDS Lake, and Mellan Hill. A multispectral survey collects data related to the reflectivity of materials on the ground surface. Multispectral surveys have been successfully used to identify areas of human activity (e.g., disturbed ground, excavations, vehicle paths, etc). Multispectral survey imagery can also be used to identify the differences in natural geologic materials. Historical features such as evidence of excavations that are not visible in natural reflected-light photographs may be clearly visible in multispectral images. Multispectral imagery will be used during the review and interpretation of geophysical and radiological survey results to assist in identification of potential target areas for more detailed field investigation.

\section{$\underline{\text { Radiological, Unexploded Ordnance and Geophysical Surveys }}$}

Radiological surveys will be conducted on Antelope Lake, Brownes Lake, Pedro Lake, and NEDS Lake to map the surface and shallow subsurface distribution of radioactive debris to support the corrective action investigation and remediation of CAU 484. The purpose of these initial radiological surveys is to obtain preliminary information to define the CAU 484 scope and scale of the corrective action investigation and remediation program. The objective of the $r$ 
adiological program is to map areas with elevated gamma activity due to meta-stable Protactinium-234 (DU daughter product) or other gamma-emitting radionuclides. Areas located from these surveys and identified as site targets will be examined in further detail during the corrective action investigation.

The radiological survey will consist of ground-based measurements using an RSL vehicle (Kiwi) equipped with a data acquisition system and six sodium iodide gamma detectors arrayed to survey an area $3 \mathrm{~m}$ (10 ft) wide. Surveys will be conducted with the vehicle moving at a rate of approximately 16 kilometers per hour (10 miles per hour) with the gamma detectors positioned approximately 70 centimeters ( 28 inches) above the ground surface. This will give a sensitivity of 10 milliCuries which equates to approximately 30 grams or 1.5 cubic centimeters of DU. The detector height may be lowered to approximately 36 centimeters (14 inches) above the ground surface for an expected sensitivity of 1 milliCurie, approximately 3 grams or 0.15 cubic centimeters of DU.

Detector positioning information is provided by a real-time differential global positioning system (RDGPS). Latitude and longitude coordinates are recorded every second for post-survey analysis. The vehicle operator is guided along the desired survey path in real time by the RDGPS, which provides visual indications of vehicle deviation from the desired survey path. Under some circumstances, where straight line navigation is impossible (washes, rocks, bushes, and other obstacles), the vehicle operator will follow the tire tracks of the previous transect to guarantee adequate coverage of the study area. The actual recorded path, not the planned path, is used for final data analysis.

The geophysical survey will consist of an electromagnetic (EM) survey conducted simultaneously with the radiometric survey in order to minimize positioning errors and to generate a complimentary data set. The EM survey will be conducted concurrently with the radiometric survey using Geonics® EM-61 MK2 high power time domain metal detectors. The detector coils will be operated as a time synchronized array and will record four time gates of data per coil. The array will be towed behind the Kiwi vehicle with the coils oriented for maximum spatial coverage.

Before conducting the radiological and geophysical drive-over surveys, and Unexploded Ordnance (UXO) assessment of the areas will be made. The UXO assessment will be made by a certified Explosive Ordnance Disposal (EOD) technician and will consist of a visual inspection of survey areas. Any potential UXO identified by the EOD technician will be marked so that it is easily seen, its location documented using GPS equipment, and the appropriate TTR Sandia personnel will be informed. No other activities to mitigate the hazard, such as neutralizing or disposing of the UXO, will be performed by any site personnel.

\section{$\underline{\text { Data Integration and Utilization }}$}

Drive-over radiological survey data, geophysical survey data, aerial photography, and multispectral imagery will be compiled and reviewed to support the corrective action investigation and remediation activities.

The compiled data will be used to delineate the extent of any remaining detonation-related debris and potentially associated DU and beryllium at CAS TA-52-001-TANL (NEDS Detonation Area), 
TA-52-004-TAAL (Metal Particle Dispersion Test), and TA-52-006-TAPL (Depleted Uranium Site). The survey data will be used to define the CAS boundaries at the surface detonation sites, and EM to aid in the location of particles of DU for cleanup. Data interpretations will be presented to NNSA/NSO prior to proceeding with the corrective actions.

Sites with potential surface and/or subsurface debris will be evaluated to locate potential areas of interest on the lake beds. Approximately the north half of Antelope Lake will be included in the surveys and will cover the entire area identified as potentially containing the DU rings associated with CAS TA-52-005-TAAL (Joint Test Assembly DU Sites). Up to three targets that potentially represent the DU rings may be identified for further investigation. Potential Davis Gun (CAS RG-52-007-TAML) locations on Antelope Lake, Brownes Lake, Pedro Lake, and NEDS Lake will be evaluated using the survey data to identify areas of debris, radiological material, and/or buried metallic objects.

Geophysical and radiological survey data will be used to define the scope of investigation and cleanup required for the Davis Gun sites located on the dry lake beds.

It should be noted that conducting surveys over such a large area with an approximately 50-year history of testing activity may identify multiple sites of interest (e.g., areas of disturbed ground, buried metallic objects, surface and shallow subsurface radiological material, etc.) that are not related to the CASs in CAU 484. While it is unknown how many targets will be identified during the drive-over surveys, only those that are most likely to contain waste as described by the FFACO as being associated with CAU 484 will be investigated further and/or closed as part of CAU 484.

\subsection{CONTAMINANTS OF POTENTIAL CONCERN}

Based on site process knowledge and historical information, the COPCs associated with sites included in CAU 484 are DU and beryllium. An unconfirmed sealed Co-60 radiological source that may be present at the Colimbo site is not considered a COPC, but will be removed if located. Based on process knowledge it is anticipated that the DU contamination will consist of discrete pieces of intact or fragmented DU. Beryllium distribution is assumed to be related to that of DU. However, beryllium is a brittle metal and has the possibility to readily fragment into small pieces and is more likely to impact the soil in the detonation area. Waste may also consist of non-impacted debris associated with test articles. Table 1 includes a description of the COPCs and impacted and/or non-impacted debris that may be present at CASs in CAU 484. 
TABLE 1. WASTE/CONTAMINANTS OF POTENTIAL CONCERN

\begin{tabular}{|c|c|c|c|c|c|}
\hline \multirow[t]{2}{*}{ CAS NUMBER } & \multirow[t]{2}{*}{$\begin{array}{c}\text { CAS } \\
\text { DESCRIPTION }\end{array}$} & \multicolumn{2}{|c|}{\begin{tabular}{|c|} 
CONTAMINANTS OF \\
POTENTIAL \\
CONCERN \\
\end{tabular}} & \multirow{2}{*}{\begin{tabular}{|c|} 
IMPACTED/N \\
ON-IMPACTE \\
D DEBRIS
\end{tabular}} & \multirow[t]{2}{*}{$\begin{array}{l}\text { CONTAMINANT/WASTE } \\
\text { DESCRIPTION }\end{array}$} \\
\hline & & $\begin{array}{l}\text { Depleted } \\
\text { Uranium }\end{array}$ & Beryllium & & \\
\hline RG-52-007-TAML & Davis Gun Sites & Unknown & N/A & Unknown & $\begin{array}{l}\text { DU/inert debris on the ground surface or } \\
\text { shallow subsurface }\end{array}$ \\
\hline TA-52-001-TANL & $\begin{array}{c}\text { NEDS Detonation } \\
\text { Area }\end{array}$ & Yes & Yes & N/A & $\begin{array}{l}\text { DU and beryllium dispersed on the } \\
\text { ground surface }\end{array}$ \\
\hline TA-52-004-TAAL & $\begin{array}{c}\text { Metal Particle } \\
\text { Dispersion Test } \\
\end{array}$ & Yes & Yes & N/A & $\begin{array}{l}\text { DU and beryllium dispersed on the } \\
\text { ground surface }\end{array}$ \\
\hline TA-52-005-TAAL & $\begin{array}{c}\text { Joint Test } \\
\text { Assembly Sites }\end{array}$ & Yes & N/A & N/A & $\begin{array}{l}\text { DU rings on the ground surface or } \\
\text { shallow subsurface }\end{array}$ \\
\hline TA-52-006-TAPL & Colimbo Site & Yes & Yes & Unknown & $\begin{array}{l}\text { DU and beryllium dispersed on the } \\
\text { ground surface. } \\
\text { (An unconfirmed sealed Co- } 60 \text { source } \\
\text { may also be present at the Colimbo site.) }\end{array}$ \\
\hline TA-54-001-TANL & $\begin{array}{l}\text { Tank and Steel } \\
\text { Structure }\end{array}$ & N/A & N/A & Yes & $\begin{array}{l}\text { Non-impacted debris on the ground } \\
\text { surface }\end{array}$ \\
\hline
\end{tabular}

\subsection{REMEDIATION}

Remedial activities associated with the closure of CAU 484 are discussed below and are grouped by CSM due to the similarity of expected closure methods to be used. Closure activities will be an iterative process completed in two phases. The first phase will involve data collection during the corrective action investigation to verify the CSMs. Data collection may consist of sample collection, field surveys, and/or other data collection methods. Assuming the conceptual site models are verified, sites with COCs present above action levels and/or detectable concentrations of DU will be clean closed. Sites with no COCs or COCs below action levels will be closed by taking no further action. If the DU rings in CAS TA-52-005-TAAL (Joint Test Assembly Sites) are not located, the site will be closed using the precedent set by CAU 495 where the CAS may be closed by no further action with the caveat that it will be reopened if additional information concerning the site is found in the future. Surveys and sampling may be completed as determined necessary by the Technical Lead/Task Manager and discussions with the NNSA/NSO TM. Screening and/or sampling may be completed outside the CAS boundaries to establish background concentrations of COPCs within the study area at TTR.

\subsubsection{Surface Detonation Debris Sites}

Based on the background information, the COPCs at three CASs include DU fragments and beryllium resulting from a surface detonation and dispersal of test article components. The presence and extent of the COPCs at the CASs will be determined during the field activities. Any COPCs detected at these 
sites will likely be in the form of discrete fragments on the ground surface, so a hot-spot cleanup approach will be used. Corrective actions detailed below apply to the following three CASs:

- CAS TA-52-001-TANL, NEDS Detonation Area.

- CAS TA-52-004-TAAL, Metal Particle Dispersion Test.

- CAS TA-52-006-TAPL, Depleted Uranium Site.

\subsubsection{Surface Detonation Debris Sites Survey and Sampling Activities}

Field activities will be completed for the three CASs included within the Surface Detonation Debris CSM. The field activities may include surveys, screening, and/or sample collection for laboratory analysis for the verification and delineation of COPCs. The field activities will be completed as described in the following subsections.

\section{Determination of the Presence of COPCs}

The presence of COPCs will be confirmed during the field activities. The presence of DU will be identified by geophysical and radiological drive-over surveys. Additional surveys using portable radiological instruments may be completed to delineate and verify DU extent. Soil samples may also be collected and analyzed to determine DU concentrations. The presence of beryllium will be determined by the collection and laboratory analysis of soil samples from the area of detonation at each CAS.

\section{Determination of the Horizontal and Vertical Extent of COPCs}

If DU is the only COPC confirmed at a site, the horizontal extent of DU impact will be determined using the geophysical and radiological survey methods described below. Soil samples may also be collected for laboratory analysis to determine DU concentrations and distribution.

Geophysical surveys (EM and Radiological) will be used to determine the presence and lateral extent of areas containing surface or near-surface metallic objects/debris and radiological materials as described in section 3.0. Additional geophysical methods may be used as needed to better refine the CAS boundaries and/or location.

Based on site conditions and available data, field-screening activities may be conducted for alpha and beta/gamma radiation. Handheld radiological survey instruments or methods may be used as needed to complete the field activities. If determined appropriate, on-site gamma spectrometry may also be used to screen samples. Soil samples may be collected and submitted for laboratory analysis to verify radiological field survey results.

Depleted uranium located and documented during radiological surveys of the Surface Detonation Debris Areas will be identified for localized "hot spot" cleanup during remediation activities. Soil samples will be collected from the detonation sites to augment the radiological survey data and determine if DU and/or beryllium above action levels is present in the soil within the boundaries of the CASs. Soil samples will be collected from random and biased locations. 
Hand sampling, augering, direct push, excavation, drilling, or other appropriate sampling methods may be used to collect soil samples for laboratory analysis. Sample collection and handling activities will be conducted in accordance with approved procedures. Soil samples will be collected (from CASs grouped within the Surface Detonation Debris CSM) from biased and random locations after potential target areas have been determined from process knowledge, and geophysical and radiological survey data. Soil samples will not be collected from "hot spot" locations identified during surface survey activities (further investigation is not needed once a DU "hot spot" has been identified). If a random sampling location plots within the impacted area of a "hot spot," the sample will not be collected and an alternate random location will be selected. The sampling will be conducted in accordance with the statistical model presented in the CAU 484 DQOs.

The statistical model applies to potential beryllium and DU contamination within the "Surface Detonation ce for Choosing a Sampling Design for Environmental Data Collection (EPA, 2002a) defines the methodology suggested to determine the sufficient number of samples to be collected to ensure a 95 percent confidence level in the COPCs concentration. This methodology has been used to determine the number of sampling locations required at sites potentially impacted by beryllium in CAU 484. The number of samples required may be determined using the following equation and the coefficient of variation (CV) of existing analytical data:

$\mathrm{n}=\mathrm{t}_{\mathrm{a}}^{2}(\mathrm{CV})^{2} / \mathrm{p}^{2}$

Where:

$\mathrm{n} \quad=$ number of samples

$\mathrm{t}_{\mathrm{a}} \quad=\mathrm{T}$ statistic for a $95 \%$ confidence level

$\mathrm{CV}=$ coefficient of variation

$\mathrm{p} \quad=$ margin of error

Upon completion of the soil sampling effort, the data obtained for the COCs will be reviewed. It will then be determined if an adequate number of samples have been collected with respect to the margin of error and confidence selected during the planning process. If the collection of additional samples is deemed necessary, the data that has been generated may be used to plan for a more efficient and cost-effective re-sampling of the site.

Beryllium and isotopic uranium analytical data collected from CAU 529 (Area 25 Contaminated Materials) CAS 25-23-17 (Contaminated Wash) will be used to calculate an estimate of the number of samples needed for CAU 484. Soil samples for beryllium and DU analysis will be collected concurrently; therefore, the most conservative CV within the CAU 529 beryllium and DU data will be used to estimate the number of samples to be collected at the Surface Detonation Debris Sites in CAU 484. CAU 529 has been selected because contamination at this site was the result of a detonation of a test article containing similar material to that used during testing activities at the Surface Detonation Debris sites within CAU 484. Analytical data from samples collected at CAU 484 sites will be statistically analyzed and evaluated to confirm a sufficient number of samples have been collected and data meets project objectives. 
Due to the nature of the event (detonation of a test article from a point source) beryllium and DU concentrations are assumed to be normally distributed on the ground surface with the highest concentration occurring near the point of detonation and decreasing in all directions away from the point source. The sampling plan includes a combination of biased and random sample locations. Random sample locations will be selected using a grid and a random number generator. Biased samples will be collected near the point of detonation. Additional biased samples may be collected at the discretion of the Technical Lead/Task Manager. A surface and shallow subsurface soil sample will be collected from each location. Surface samples will be collected from the ground surface to a depth not to exceed 0.2 $\mathrm{m}(0.5 \mathrm{ft})$ below ground surface (bgs) and subsurface samples will be collected from a depth of approximately 0.3 to $0.5 \mathrm{~m}$ (1.0 to $1.5 \mathrm{ft}$ ) bgs. If laboratory analysis of soil samples indicate beryllium and/or DU is present at concentrations above the action levels then additional step-out samples will be collected to bound the impacted area.

\subsubsection{Surface Detonation Areas Remediation}

The preferred closure alternative for sites within the Surface Detonation Debris CSM is clean closure. The following subsections describe the planned methods of removing DU, beryllium, and associated impacted soil at the sites associated with a surface detonation.

\section{Clean Closure Activities for DU}

Depleted uranium fragments "hot spots" detected during the surveys will be removed from the ground surface for disposal. No excavation is anticipated, as the DU impact is anticipated to be restricted to the ground surface as a result of dispersal tests. If necessary, potentially impacted soil associated with the DU will also be removed and placed into the appropriate containers.

\section{Clean Closure Activities for Beryllium}

Beryllium fragments detected during the surveys will be removed from the ground surface for disposal. Areas of beryllium-impacted soil over the action level will be removed and placed into the appropriate containers.

\section{Clean Closure Activities for Impacted/Non-impacted Debris}

Impacted/non-impacted debris identified for removal during CAU 484 closure activities will be placed in the appropriate containers.

\section{$\underline{\text { Verification of Clean Closure Activities }}$}

Depleted uranium cleanup will be verified using field radiological survey methods. An approach similar to that used to characterize, remove, and verify cleanup of DU at CAU 425 (NNSA/NSA, 2003) will be used at CAU 484. Soil samples may also be collected and submitted for laboratory analysis to confirm cleanup levels have been met. Cleanup of beryllium will be verified by collecting soil samples for laboratory analysis and comparison of results to the action level. Removal of impacted and/or non-impacted surface debris will be verified using field screening techniques and photographic documentation. 
$\underline{\text { Waste Disposal }}$

Waste generated during CAU 484 closure activities will be containerized, properly managed, and transported to an appropriate disposal and/or recycling facility.

\subsubsection{Closure by No Further Action}

The location of the three CASs included in the Surface Detonation Debris Sites CSM are well documented. If no DU or beryllium is found to be present at these sites, the CASs will be closed by taking no further action.

\subsubsection{Surface-Shallow Subsurface Debris Areas}

The Surface-Shallow Subsurface Debris CSM includes the following two CASs:

- CAS RG-52-007-TAML, Davis Gun Penetrator Test

- CAS TA-52-005-TAAL, Joint Test Assembly DU Sites

Based on background information the potential COPC present at these CASs is DU which has been released to the environment as a result of testing activities conducted at TTR. Due to the nature of testing activities at the surface-shallow subsurface sites, DU may be present in discrete fragments and/or intact pieces (e.g., DU rings). The presence of DU will be determined by the results of the EM and radiological (Kiwi) drive-over surveys. Soil samples may be collected and analyzed to confirm DU concentrations. Investigation and remediation of Surface-Subsurface Debris Areas will be completed as described below.

\subsubsection{Surface-Shallow Subsurface Debris Areas Investigation}

The field activities at the CASs within the Surface-Shallow Subsurface Debris CSM will include surveys, screening, and/or sampling and analysis as needed to confirm the presence and extent of DU. The field activities will be completed as described in the following subsections.

Confirming the presence of DU

The potential presence of DU at these sites will be determined during the field activities. The presence of DU will be identified during the geophysical and radiological surveys and verified using portable radiological instruments. Some limited excavation may be required to expose areas potentially containing DU. Potential Davis Gun Penetrator Test locations outside of the dry lakebeds will be visually inspected to determine if testing occurred. Locations outside of the dry lakebeds where Davis Gun Penetrator Tests did occur will be evaluated using radiological and geophysical techniques to determine if DU remains at the sites.

Locating the Horizontal and Vertical Extent of DU

If DU is determined to be present at one or more of the locations identified for these CASs, its presence will be confirmed by the following methods. Some excavation may be required to expose the DU and confirm its location and extent. 
Geophysical surveys (EM and Radiological) will be used to determine the presence and lateral extent of areas containing surface-shallow surface metallic objects/debris and radiological materials as described in section 3.0. Additional geophysical and/or radiological methods may be used as needed to better refine the CAS boundaries and/or location.

Based on site conditions and available data, field-screening activities may be conducted for alpha and beta/gamma radiation. Handheld radiological survey instruments or methods may be used as needed to complete the field activities. If determined appropriate, on-site gamma spectrometry may also be used to screen samples.

\subsubsection{Surface-Shallow Subsurface Debris Area Remediation}

\section{Clean Closure Activities for DU}

Depleted uranium pieces detected during the surveys will be treated as localized hot-spots where the DU and the soil immediately surrounding it will be removed for disposal.

\section{$\underline{\text { Verification of Clean Closure Activities }}$}

Depleted uranium cleanup will be verified using field survey methods. An approach similar to that used to characterize, remove, and verify cleanup of DU at CAU 425 (NNSA/NSA, 2003) will be utilized at CAU 484. Soil samples may also be collected from the area where DU was removed to confirm cleanup verification.

\section{$\underline{\text { Waste Disposal }}$}

Waste generated during CAU 484 closure activities will be containerized, properly managed, and transported to an appropriate landfill for disposal.

\section{$\underline{\text { Regrading/Backfilling Excavation with Clean Fill }}$}

If the excavation is shallow, the area will be regraded without the addition of clean fill. If a substantial volume of material has been removed from an excavation, clean fill will be added as appropriate to bring the area to surrounding grade. The excavation will be backfilled using a front-end loader or equivalent equipment. Material placed into the excavation will be compacted by wheel rolling over the excavation. If necessary, water will be sprayed onto the fill material during the backfill activity to reduce dust and promote compaction.

\subsubsection{Closure by No Further Action}

If no potential targets are identified that could possibly be related to the Surface-Shallow Subsurface Debris Sites, the "no further action" closure alternative will be selected based on the approach previously approved by NDEP for CAS 495 (Unconfirmed Joint Test Assembly Sites(TTR)). This approach will allow closure of the unconfirmed site with no land/site use restrictions and no post-closure monitoring. However, if additional evidence becomes available in the future which indicates the location of the site, the site will be reopened to continue the investigation. 


\subsubsection{Non-Impacted Surface Debris Site}

CAS TA-54-001-TANL (Containment Tank and Steel Structure) consists of non-hazardous wood and steel structures and materials. After a review of the structures for historical significance, this CAS will be clean-closed by removal and disposal or recycling of the materials.

\subsection{VERIFICATION}

\subsubsection{Depleted Uranium and Beryllium}

Verification of DU cleanup will be achieved by using field survey methods. An approach similar to that used to characterize, remove, and verify cleanup of DU at CAU 425 (NNSA/NSA, 2003) will be used at CAU 484. Soil samples may also be collected to verify clean closure of DU-impacted sites. Soil samples will be collected for laboratory analysis to verify clean closure of beryllium-impacted sites. Depleted uranium and beryllium analytical results will be compared to the appropriate action level. The number of verification samples will be based on the previously discussed statistically-based approach. Verification sampling locations will include both random and biased locations.

\subsubsection{Non-Impacted Surface Debris}

Verification of non-impacted surface debris clean closure will be verified through field and photographic documentation of the cleanup activities. No screening, survey, or sampling is required.

\subsection{DATA QUALITY OBJECTIVES}

DQOs are qualitative and quantitative statements that specify the quality of the data required to support potential closure alternatives for CAU 484. The DQOs were developed to clearly define the purposes for which environmental data will be used and to design a data-collection program that will satisfy these purposes. The formulation of CSMs is an aid to the development of DQOs for the site.

Details of the DQO process are presented in Appendix A1. During the DQO discussions for CAU 484, data needed to resolve problem statements and decision statements were identified. Criteria for data collection and analysis were defined and agreed upon, and the appropriate quality assurance (QA)/quality control (QC) required for particular data collection activities was assigned. The analytical methods and reporting limits prescribed through the DQO process and the data quality indicators (DQIs) for laboratory analysis, such as precision and accuracy requirements, are provided in more detail in Section 6.0.

\subsection{CLOSURE}

The specific activities required to close each CAS in CAU 484 are detailed in Section 3.2. Hold points and conditions that are outside the assumptions of this plan may impact the requirements for closure. In general, the proposed activities for closure of CAU 484 include the following:

- For CASs that are to be clean-closed, DU fragments, limited volumes of DU-impacted soil, and/or beryllium fragments, and beryllium-impacted soil will be identified and removed from the ground surface and/or excavated if necessary; 
- All removed soil/material containing DU will be packaged as low level waste, loaded, and transported to the Nevada Test Site (NTS) for disposal;

- All excavations will be backfilled with clean fill, if necessary; and

- A Closure Report will be prepared and submitted to the NDEP for approval.

\subsection{DURATION}

The schedule will require modifications if conditions exist that are outside the assumptions on which the schedule was developed. Flexibility has been placed in the project schedule to account for minor difficulties (e.g., weather, equipment breakdowns, personnel availability, TTR operational and security constraints). NNSA/NSO will keep the NDEP informed of any condition that may impact the project schedule. Figure 10 presents the proposed project schedule following submittal of the final SAFER Plan for CAU 484. 


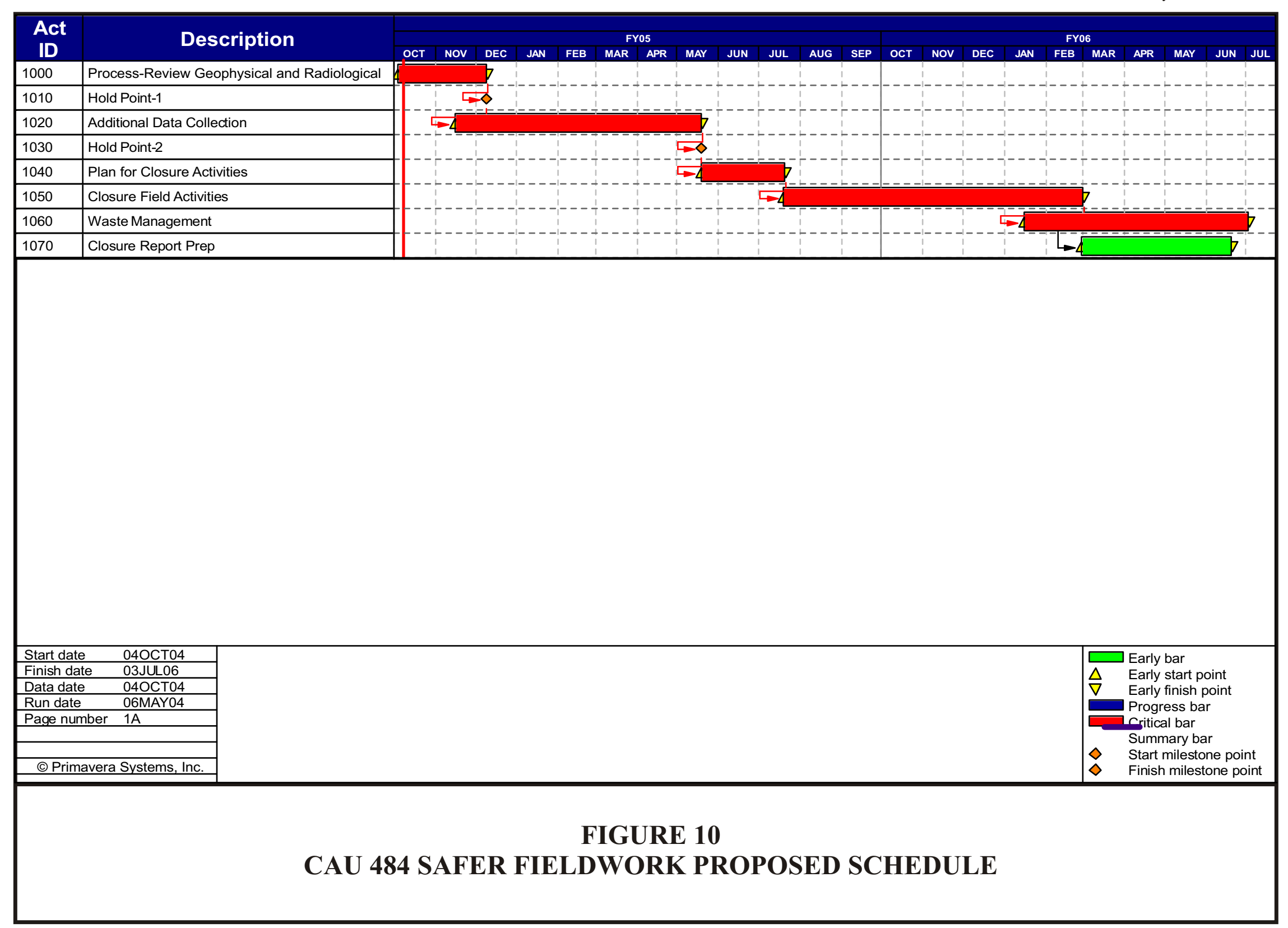




\subsection{REPORTS AND RECORDS AVAILABILITY}

A daily report will be prepared when field activities have started. The report will summarize the daily activities, site visitors, health and safety issues, and any other relevant issues or problems. This report will be provided to the NNSA/NSO Task Manager.

Upon completion of closure activities, a Closure Report (CR) will be prepared and will include the following sections and subsections:

- Introduction (Purpose and Scope)

- Closure Activities (Description of Corrective Action Activities, Deviation from the SAFER Plan as Approved, Corrective Action Schedule as Completed, and Site Plan/Survey Plan)

- Waste Disposition

- Closure Verification Results (Data Quality Assessment and Use Restrictions)

- Conclusions and Recommendations

- References

- Supporting Documentation (Analytical Results for Verification Samples, Summary of Geophysical/Radiological Survey Results, Waste Disposition Documentation, and Modifications to the SAFER Plan)

The final CR will be submitted to NNSA/NSO and NDEP for review and approval. This SAFER Work Plan and the subsequent CR will be available in the NNSA/NSO Public Reading Facilities in Las Vegas, Nevada and Carson City, Nevada, or by contracting the NNSA/NSO Project Manager. 
SAFER PLAN - CAU 484

Section: Reports \& Records

Revision: 0

Date: May 2004

THIS PAGE INTENTIONALLY LEFT BLANK 


\subsection{INVESTIGATION/REMEDIATION WASTE MANAGEMENT}

Waste from CAU 484 will be managed in accordance with all state and federal regulations, DOE orders, and BN procedures. Potential waste types will include low-level radioactive waste, beryllium-impacted waste, and sanitary waste.

\subsection{WASTE MINIMIZATION}

Waste generation will be minimized for the duration of the project by site workers adhering to the principles of the BN Waste Minimization and Pollution Prevention Program. Care will be taken to segregate waste from non-waste materials when possible and to avoid cross-contamination of waste streams.

\subsection{POTENTIAL WASTE STREAMS}

The potential waste streams generated during investigation and/or clean closure of CASs in CAU 484 include non-impacted debris (sanitary waste and surface debris), radiologically-impacted waste (DU and sealed C0-60 source), and beryllium-impacted waste. No hazardous waste is expected to be generated during CAU 484 closure activities. No waste is expected to be generated any CAS to be closed by taking no further action. Table 2 shows the potential waste streams anticipated to be generated during closure of CAU 484.

TABLE 2. POTENTIAL WASTE STREAMS BY CAS AT CAU 484

\begin{tabular}{||l|c|c|c||}
\hline \multicolumn{1}{|c|}{ CAS } & $\begin{array}{c}\text { Non- } \\
\text { Impacted }\end{array}$ & $\begin{array}{c}\text { Radiologically- } \\
\text { Impacted }\end{array}$ & $\begin{array}{c}\text { Beryllium- } \\
\text { Impacted }\end{array}$ \\
\hline TA-52-001-TANL (NEDS Detonation Area) & $\mathrm{X}$ & $\mathrm{X}$ & $\mathrm{X}$ \\
\hline $\begin{array}{l}\text { TA-52-004-TAAL (Metal Particle Dispersion } \\
\text { Test) }\end{array}$ & - & $\mathrm{X}$ & $\mathrm{X}$ \\
\hline $\begin{array}{l}\text { TA-52-005-TAAL (Joint Test Assembly DU } \\
\text { Sites) }\end{array}$ & - & $\mathrm{X}$ & $\mathrm{X}$ \\
\hline TA-52-006-TAPL (Depleted Uranium Site) & - & $\mathrm{X}$ & - \\
\hline RG-52-007-TAML (Davis Gun Penetrator Test) & $\mathrm{X}$ & - & - \\
\hline $\begin{array}{l}\text { TA-54-001-TANL (Containment Tank and Steel } \\
\text { Structure) }\end{array}$ & $\mathrm{X}$ & $\mathrm{X}$ & \\
\hline
\end{tabular}

Note: Dashes indicate no waste generated; $\mathrm{X}$ indicates potential waste generation. 


\subsubsection{Nonhazardous Waste}

Nonhazardous waste will be generated during closure of CAU 484, and will consist of construction-type debris removed from the northern area of NEDS Lake, potentially beryllium-impacted waste, and potentially miscellaneous surface debris at various sites. Additionally, used personal protective equipment (PPE) may be generated during closure activities. This type of debris will be recycled when possible. Non-recyclable materials may be disposed of in the TTR Sanitary Landfill.

\subsubsection{Radiological Waste}

Depleted uranium fragments will be removed as discrete pieces. However, some soil immediately surrounding the fragments may also be removed to ensure clean closure. The DU and any associated soil will be packaged as low-level radioactive waste and shipped to the NTS for disposal. If the sealed Co-60 radiological source is located on NEDS Lake, it will be packaged and properly managed.

\subsection{CONTAINER MANAGEMENT}

During this project 208-liter (55-gallon) drums (or other approved containers such as roll-offs, soft-sided containers, etc.) may be used. All containers must be in good condition. The containers must always be closed while stored unless waste is being added or removed. They must be handled in such a manner that will not jeopardize the integrity of the container. Containers will not be filled above their specified weight capacity. Compactable waste will then be placed in 208-liter (55-gallon) drums. After a container has been filled, the container will be locked. Containers not filled to capacity at the end of a workday will be locked. Additional precautions include not filling 208-liter (55-gallon) drums more than 7/8 full and not mixing waste types (e.g., PPE and decontamination water).

Because the majority of the waste produced during this project is anticipated to be debris with minimal amounts of soil, secondary containment will not be required. If, however, free liquids, such as decontamination water are placed in containers, the containers will be placed on spill containment pallets or within a plastic-lined bermed area. Appropriate labels and relevant information will be marked on each container with an indelible marker and must be legible and clearly visible for inspections. Pertinent information will be written on tape, a blank adhesive label, or directly onto the side of the drum. The following information will be included:

- Waste-tracking label

- Type of waste in the container (e.g., marked AHazardous Waste@

- Location where waste was derived

- Date that accumulation begins/ends

- If sampling is required, an AAwaiting Analysis@ticker after sampling has been completed 


\subsection{QUALITY ASSURANCE/QUALITY CONTROL}

The overall objective of the closure activities described in this plan is to collect accurate and defensible data to support the selection and implementation of closure alternatives for the CASs in CAU 484. The following sections discuss the collection of required QC samples in the field and QA requirements for laboratory/analytical data to achieve closure.

\subsection{PROPOSED FIELD SAMPLE COLLECTION ACTIVITIES}

Field QC samples will be collected in accordance with established procedures (BN, 2000) and the Industrial Sites Quality Assurance Project Plan (NNSA/NV, 2002). Field QC samples are collected and analyzed to aid in determining the validity of sample results. The number of required QC samples depends on the type and number of environmental samples collected. The minimum frequency of collecting and analyzing QC samples for this investigation include:

- Field duplicates (1 per 20 environmental samples or 1 if less than 20 are collected)

- Matrix spike/matrix spike duplicate (1 per 20 environmental samples or 1 if less than 20 are collected)

Additional QC samples may be collected, based on site conditions, at the discretion of the Technical Lead/Task Manager. Field QC samples will be analyzed using the same analytical procedures used for environmental samples. The results of the QC sample analysis will be included in the CR.

\subsection{PROPOSED LABORATORY/ANALYTICAL DATA QUALITY INDICATORS}

Data Quality Objectives are qualitative and quantitative statements that specify the quality of the data required to support closure of a site. The DQOs for the CAU 484 investigation were defined using the Seven Step DQO Process developed by the U.S. Environmental Protection Agency (EPA, 2000). Three Conceptual Site Models for the CAU 484 CASs were defined during the DQO process.

Clean closure of CAU 484 will require the collection and analysis of verification soil samples for DU and beryllium. All laboratory data generated during closure activities will be reviewed by project personnel to ensure the data are usable and complete according to the CAU 484 DQOs. In addition, as specified in the Industrial Sites Quality Assurance Project Plan (NNSA/NV, 2002) a minimum of 5 percent of the final data packages will be validated using applicable BN Operating Instructions. These include OI-2151.303 (BN, 2004) for validating radiological data, and OI-2154.459 (BN, 2003) for validating inorganic chemical data. Operating Instruction OI-2154.459 is based on EPA Functional Guidelines (EPA, 1994). More details on the proposed number and location of the verification samples are given in Section 3.2 of this plan.

DQIs are qualitative and quantitative statements that specify the data requirements of a project and include precision, accuracy, representativeness, completeness, and comparability.

In addition, sensitivity has been included as a DQI for laboratory analysis. The performance criteria for each indicator have been selected based on the intended use of the data, current field and analytical procedures, and instrumentation. Precision and accuracy goals have been standardized for both organic 
and inorganic analytes for analytical laboratories under the EPA Contract Laboratory Program. Laboratory QC samples used to measure the precision and accuracy of analytical procedures will be analyzed using the same analytical procedures used for environmental samples.

Table 3 provides the established performance criteria for each of the DQIs and the impacts to the decision if the criteria are not met. Any deficiencies noted during the investigation that render the data quality unacceptable will be documented in the CR. 


\section{TABLE 3. LABORATORY/ANALYTICAL DATA QUALITY INDICATORS}

\begin{tabular}{|c|c|c|}
\hline $\begin{array}{c}\text { DATA } \\
\text { QUALITY } \\
\text { INDICATOR }\end{array}$ & PERFORMANCE CRITERIA & $\begin{array}{c}\text { IMPACT ON DECISION IF } \\
\text { PERFORMANCE CRITERIA NOT } \\
\text { MET }\end{array}$ \\
\hline Precision & $\begin{array}{l}\text { Variations between duplicates (field } \\
\text { and lab) and original sample should } \\
\text { not exceed analytical } \\
\text { method-specific criteria. }\end{array}$ & $\begin{array}{l}\text { Estimated data within sample delivery group } \\
\text { (SDG) will be evaluated for their usability. If } \\
\text { data are determined to be unusable, data will } \\
\text { not be used in decision and completeness } \\
\text { criteria will be assessed. }\end{array}$ \\
\hline Accuracy & $\begin{array}{l}\text { Laboratory control sample results } \\
\text { and matrix spike results should be } \\
\text { within analytical method-specific } \\
\text { criteria. }\end{array}$ & $\begin{array}{l}\text { Estimated data within SDG will be evaluated } \\
\text { for its usability. If estimated data are biased } \\
\text { high or conservative, the data may be used in } \\
\text { decision. If estimated data are biased low and } \\
\text { below the decision threshold, the data may not } \\
\text { be used in decision and completeness criteria } \\
\text { will be assessed. }\end{array}$ \\
\hline Sensitivity & $\begin{array}{l}\text { Detection limits of laboratory } \\
\text { instruments must be less than action } \\
\text { level for COCs. }\end{array}$ & $\begin{array}{l}\text { Cannot determine if COCs are present at levels } \\
\text { of concern, thereby investigation objectives } \\
\text { cannot be met. }\end{array}$ \\
\hline Completeness & $\begin{array}{l}100 \% \text { of samples submitted to } \\
\text { laboratory } \\
100 \% \text { of requested analyses } \\
\text { performed } \\
100 \% \text { of critical analytes to be valid } \\
80 \% \text { of non-critical analytes to be } \\
\text { valid }\end{array}$ & $\begin{array}{l}\text { 1. Decision of whether extent of } \\
\text { contamination has been bounded cannot be } \\
\text { determined. Impacts to decisions will be } \\
\text { assessed. } \\
\text { 2. Decision of whether COCs above action } \\
\text { levels remain in soil cannot be determined. } \\
\text { Impacts to decisions will be assessed. }\end{array}$ \\
\hline Comparability & $\begin{array}{l}\text { Equivalent samples analyzed using } \\
\text { same analytical methods, same units } \\
\text { of measurement, and detection } \\
\text { limits must be used for like } \\
\text { analyses. }\end{array}$ & Inability to use data collected. \\
\hline $\begin{array}{l}\text { Representative- } \\
\text { ness }\end{array}$ & $\begin{array}{l}\text { Correct analytical method } \\
\text { performed for appropriate COCs: } \\
\text { valid data reflects appropriate target } \\
\text { population. }\end{array}$ & $\begin{array}{l}\text { Cannot identify COCs or estimate } \\
\text { concentration of COCs; therefore, cannot } \\
\text { make decision(s) on target population. }\end{array}$ \\
\hline
\end{tabular}

${ }^{a}$ Critical analytes are those analytes most likely present in the target population at COCs, which have been identified through process knowledge of similar sites and historical documentation. Critical analytes for samples include only beryllium. 
SAFER PLAN - CAU 484

Section: QA/QC

Revision: 0

Date: May 2004

THIS PAGE INTENTIONALLY LEFT BLANK 


\subsection{REFERENCES}

BN, see Bechtel Nevada

Bechtel Nevada. 2002a. "Sampling Chain of Custody", Organization Instruction OI-2152.100. Las Vegas, NV.

Bechtel Nevada. 2002b. "Soil Sampling", Organization Instruction OI-2152.108. Las Vegas, NV.

Bechtel Nevada. 2003. "Inorganic Data Verification and Validation", Organization Instruction OI-2154.459. Las Vegas, NV.

Bechtel Nevada. 2004. "Validation of Radiological and Chemical Laboratory Data", Organization Instruction OI-2151.303. Las Vegas, NV.

DOE/NV, see U.S. Department of Energy, Nevada Site Office.

EPA, see U.S. Environmental Protection Agency.

FFACO, see Federal Facility Agreement and Consent Order.

Federal Facility Agreement and Consent Order. 1996 (as amended). Agreed to by the State of Nevada, the U.S. Department of Energy, and the U.S. Department of Defense.

IT, see International Technology Corporation.

International Technology Corporation. 2003. Preliminary Assessment: Site Reference Summary for CAU 484, Surface Debris, Waste Sites, and Burn Area. Nevada Test Site, Project Files. Las Vegas, NV

National Council on Radiation Protection and Measurements. 1999. Recommended Screening Limits for contaminated Surface Soil and Review of Factors Relevant to Site-Specific Studies. NCRP Report No. 129. National Council on Radiation Protection and Measurement, Bethesda, MD.

NNSA/NSO, see U.S. Department of Energy, National Nuclear Security Administration Nevada Site Office.

U.S. Department of Energy, (DOE). 1993. "Radiation Protection of the Public and the Environment". DOE Order 5400.5 Change 2.

U.S. Department of Energy, Nevada Operations Office. 2000. NV/YMP Radiological Control Manual, Revision 4, DOE/NV/11718-079, Las Vegas, Nevada. 


\subsection{REFERENCES (continued)}

U.S. Department of Energy, National Nuclear Security Administration Nevada Operations Office. 2002. Industrial Sites Quality Assurance Project Plan, Nevada Test Site, Nevada, Rev. 3, DOE/NV--372. Las Vegas, NV.

U.S. Department of Energy, National Nuclear Security Administration Nevada Site Office. 2003. Closure Report for Corrective Action Unit 425: Area 9 Main Lake Construction Debris Disposal Area, Tonopah Test Range, Nevada. DOE/NV--875. Las Vegas, NV.

U.S. Environmental Protection Agency. 1994. Contract Laboratory Program National Functional Guidelines for Inorganic Data Review, EPA/540/R-94/013. Washington, DC.

U.S. Environmental Protection Agency. 2000. Guidance for Data Quality Assessments: Practical Methods for Data Analysis, EPA QA/G-4, EPA/600/R-96/055. Washington, DC.

U.S. Environmental Protection Agency. 2002a. Guidance on Choosing a Sampling Design for Environmental Data Collection. EPA QA/G-5S. Washington, D.C.

U.S. Environmental Protection Agency. 2002b. Region IX Preliminary Remediation Goals (PRGs). October. San Francisco, CA.

U.S. Geological Survey. 1971. Geology of Northern Nellis Air Force Base Bombing and Gunnery Range, Nye County, Nevada. Prepared by E. B. Ekren, R. E. Anderson, C. L. Rogers, and D. C. Noble for the U.S. Atomic Energy Commission. Professional Paper 651. Washington, DC. 
Date: May 2004

\section{APPENDIX A1}

\section{DATA QUALITY OBJECTIVES FOR CAU 484}


SAFER PLAN - CAU 484

Section: Appendix A1

Revision: 0

Date: May 2004

THIS PAGE INTENTIONALLY LEFT BLANK 


\section{ACRONYMS AND ABBREVIATIONS}

BN Bechtel Nevada

CAI Corrective Action Investigation

CAS Corrective Action Site

CAU Corrective Action Unit

COC Contaminants of concern

COPC Contaminants of potential concern

CSM Conceptual Site Model

$\mathrm{CV} \quad$ Coefficient of variation

DOE U.S. Department of Energy

DOE/NV U.S. Department of Energy, Nevada Operations Office

DQO Data Quality Objective(s)

DU Depleted uranium

EPA U.S. Environmental Protection Agency

FFACO Federal Facility Agreement and Consent Order

$\mathrm{ft} \quad$ foot (feet)

$\mathrm{ft}^{2} \quad$ square feet

$\mathrm{ft}^{3} \quad$ cubic feet

IT International Technology

JTA Joint Test Assembly

m meter(s)

$\mathrm{m}^{2} \quad$ square meters

$\mathrm{m}^{3} \quad$ cubic meters

MPDT Metal Particle Dispersion Test

NCRP National Council on Radiation Protection and Measurements

NDEP Nevada Division of Environmental Protection

NEDS Nonviolent Explosive Destruct System

NNSA/NSO U.S. Department of Energy, National Nuclear Security Administration Nevada Site Office

PRG Preliminary remediation goal

QA/QC Quality Assurance/Quality Control

SAFER Streamlined Approach for Environmental Restoration

TTR Tonopah Test Range 
SAFER PLAN - CAU 484

Section: Appendix A1

Revision: 0

Date: May 2004

THIS PAGE INTENTIONALLY LEFT BLANK 


\section{APPENDIX A \\ DATA QUALITY OBJECTIVES FOR \\ CORRECTIVE ACTION UNIT 484: SURFACE DEBRIS, WASTE SITES, AND BURN AREA, \\ TONOPAH TEST RANGE, NEVADA}

\section{Presentation of Known Data Related to Corrective Action Unit 484}

The information presented in this worksheet is based on historical data generated from preliminary assessment activities for Corrective Action Unit (CAU) 484 at the Tonopah Test Range (TTR). The Data Quality Objective (DQO) worksheet follows the U.S. Environmental Protection Agency (EPA) DQO guidance outline (EPA, 2000b). The steps systematically build on the data acquired during preliminary assessment work and background research. Copies of the preliminary assessment work are retained in the CAU 484 project files.

Members of the Planning Team (* indicates members present at the DQO meeting):

1. U.S. Department of Energy, National Nuclear Security Agency Nevada Site Office (NNSA/NSO) Janet Appenzeller-Wing

Kevin Cabble*

2. Bechtel Nevada (BN)

Ronald Jackson*

Reed Poderis*

Dudley Emer*

Kevin Campbell

3. Nevada Division of Environmental Protection (NDEP)

Clem Goewert*

4. Core Decision Team

Janet Appenzeller-Wing (NNSA/NSO)

Kevin Cabble (NNSA/NSO)

Brad Jackson (BN)

5. Primary Decision Makers

Janet Appenzeller- Wing (NNSA/NSO)

Kevin Cabble (NNSA/NSO) 


\subsection{STATE THE PROBLEM (Step 1)}

Concisely describe the problem to be studied. Review prior studies and existing information to gain a sufficient understanding to define the problem.

The general location, nature, and extent of the CAU 484 corrective action sites (CASs) is understood; however, additional information is needed to verify that the existing information is adequate, confirm the existence of contamination and/or waste, and/or verify previously completed cleanup activities. Information will be used to close these CASs under the Streamlined Approach to Environmental Restoration (SAFER) process.

\subsection{CAS Specific Information}

CAU 484, Surface Debris, Waste Sites, and Burn Area, is located at the TTR and consists of the following six CASs:
\$ CAS RG-52-007-TAML, Davis Gun Penetrator Test,
$\$$ CAS TA-52-001-TANL, NEDS Detonation Area,
\$ CAS TA-52-004-TAAL, Metal Particle Dispersion Test,
\$ CAS TA-52-005-TAAL, Joint Test Assembly DU Sites,
$\$$ CAS TA-52-006-TAPL, Depleted Uranium Site, and
\$ CAS TA-54-001-TANL, Containment Tank and Steel Structure.

The following sections describe the CASs in CAU 484 and the conceptual site models (CSMs) that apply to each CAS.

\subsubsection{CAS RG-52-007-TAML, Davis Gun Penetrator Test}

CAS RG-52-007-TAML, Davis Gun Penetrator Test, consists of potentially 9 locations at TTR and the Nevada Testing and Training Range (NTTR) and is identified within the Federal Facilities Agreement and Consent Order (FFACO) as Depleted Uranium (DU) Surface Debris. The potential locations where Davis Gun Penetrator tests were conducted include Antelope Tuff Target 1, Antelope Tuff Target 2, Myers Ridge, Sidewinder Tuff Target, Antelope Lake, Main Lake, Pedro Lake, Brownes Lake, and Mt. Helen (Mt. Helen was apparently erroneously reported as Mellan Hill in some documentation; no Davis Gun tests are known to have been conducted at Mellan Hill.)

The Davis Gun is a recoilless rifle used by Sandia National Laboratories to fire artillery projectiles into soil, rock, and concrete targets. According to information collected previously, the penetrators used at TTR were usually inert with the occasional use of DU as ballast. At least one test included a plutonium pit in a penetrator and was recovered intact and returned to the test customer. Historical evidence indicates that one penetrator was possibly lost in 1976 when a penetrator was reported as falling into a fracture that opened on Antelope Lake after a heavy rain. The penetrator could not be subsequently located and it is unknown if the lost penetrator contained DU or if the event actually occurred.

Release of DU is not a likely scenario at Davis Gun test locations, as there is evidence that all penetrators were recovered completely intact. The purpose of Davis Gun tests was to evaluate delivery system packages and a primary goal of the experiments was to recover the test components. 
Therefore, it is highly unlikely that test components were left at the sites where the experiments were conducted. An unrecovered penetrator would be considered a test failure and no failures for Davis Gun tests have been reported. Areas where Davis Gun tests occurred will be investigated as necessary and the appropriate corrective actions will be taken.

\subsubsection{CAS TA-52-001-TANL, NEDS Detonation Area}

The NEDS (Nonviolent Explosive Destruct System) Detonation Area is a test site located on the northern half of NEDS Lake and is identified within the FFACO as DU Surface Debris. The tests were performed in 1974 and involved exploding mock nuclear warheads using high explosive to test containment. Depleted uranium and/or beryllium were used as components within the mock warheads. Although the area was cleaned and the majority of debris was recovered after the tests, the possibility remains that residual DU and/or beryllium may remain on the playa surface in the area of the detonations. The area where the NEDS test occurred will be investigated and the appropriate corrective actions will be taken.

\subsubsection{CAS TA-52-004-TAAL, Metal Particle Dispersion Test}

The Metal Particle Dispersion Test (MPDT) is located within the northwest corner of Antelope Lake and is identified within the FFACO as DU Surface Debris. The MPDT is the site of a 1987 experiment in which a W-82 mock nuclear artillery shell was detonated with high explosive to test dispersal patterns. Depleted uranium and/or beryllium were used to simulate the dispersal of radioactive materials. The location of the test is documented and a recovery operation took place after the test to map the dispersion of the particles. A soil berm was also constructed around the area of the test. Residual radiological materials may remain within the bermed area depending on the thoroughness of the cleanup completed in1987.

\subsubsection{CAS TA-52-005-TAAL, Joint Test Assembly DU Sites}

The Joint Test Assembly (JTA) DU Sites are located within the northern portion of Antelope Lake and are identified within the FFACO as DU Surface Debris. The JTA experiments were conducted in 1987 and involved firing four W-33 mock nuclear artillery shells from a 155-millimeter howitzer. The projectiles were fired from Area 9 toward Antelope Lake. The artillery rounds reportedly contained DU rings for additional reaction mass. Interviews of project personnel indicate that at up to three of the rings were never recovered despite a 2-square mile search of the impact area on the northern portion of Antelope Lake. For this reason, DU associated with the JTA experiments may be present on the surface or shallow subsurface of the northern portion of Antelope Lake. This site is being investigated to determine if any materials from the JTA tests remain on Antelope Lake.

\subsubsection{CAS TA-52-006-TAPL, Depleted Uranium Site}

The Depleted Uranium Site is located on NEDS Lake and is identified within the FFACO as DU Surface Debris. This site is the result of the 1985 Colimbo test in which a fully configured W-81 cruise missile was detonated above the surface of NEDS Lake. Recovery and cleanup operation was conducted to remove components and debris related to the test. However, there may be residual DU and/or beryllium as well as an unconfirmed sealed cobalt radiological source remaining on the playa surface. The location of the detonation is well documented and the area will be investigated to 
determine if residual components of the Colimbo test remain at the site.

\subsubsection{CAS TA-54-001-TANL, Containment Tank and Steel Structure}

Several large pieces of debris associated with NEDS Lake operations are located at the north end of the lake. The structures are believed to have been used during the NEDS tests and have been previously evaluated and determined not to be contaminated. The tank and structure is considered nonimpacted housekeeping waste/debris and will be cleaned up accordingly. A wood and steel structure associated with CAU 410 is also present at this location and may be removed.

The CAS has been incorrectly described as containing a burn area. CAS TA-54-001-TANL was originally described and thought to have been a location for burning rocket fuel. However, burning of rocket fuel was determined not to have occurred at this location and the CAS name was changed to "Containment Tank and Steel Structure." The "containment tank" is actually designed to be used as a shelter by personnel during some type of testing activity. The use of the steel structure is unknown. However, both the containment tank and steel structure were used at different locations on the TTR and have been subsequently moved to their present location. A burn site is located on NEDS lake but it is related to training exercises conducted by TTR security forces and is not part of CAU 484 .

\subsection{Develop/Refine the Conceptual Model}

Available information from which the conceptual models are based was derived from site process knowledge, historical background information, site analysis, and personnel interviews relative to the activities related to the CAS. Three CSMs have been developed for CAU 484.

\subsubsection{Surface-Shallow Subsurface Debris CSM}

This CSM addresses areas where DU and/or system components may have been released to the ground surface or may have penetrated the shallow subsurface. A graphical depiction of the CSM is shown in Figure 1 of this appendix. Based on the types of testing activities conducted at the locations included in this CSM, if DU is detected it will be present in discrete pieces. Based on process knowledge and technology limitations, shallow subsurface is defined as being a depth of $3 \mathrm{~m}$ (10 feet [ft]) or less below ground surface. The surface and shallow subsurface will be evaluated using geophysical methods. The following sites are included within the Surface-Shallow Subsurface Debris CSM:

\subsubsection{CAS RG-52-007-TAML, Davis Gun Penetrator Test}

The locations of the Davis Gun Penetrator Test sites are primarily identified on lake beds by evidence of a circular berm (constructed to prevent storm water run-on during penetrator recovery operations) and, at locations not on lake beds, by evidence of an excavation and associated rock spoils. Small piles of rock fragment are commonly present adjacent to targets located in areas where tests were conducted in the tuff. Known or possible test locations include Antelope Tuff Target 1, Antelope Tuff Target 2, Myers Ridge, Sidewinder Tuff Target, Antelope Lake, Main Lake, Pedro Lake, Brownes Lake, and Mt. Helen. Based on the documentation, it is unlikely that any unrecovered penetrators or fragments remain below the surface. However, the CAS is listed as potential surface contamination because it is known that the DU that was occasionally used as ballast in the penetrator projectiles. These areas are not located within known radiological control areas and contaminants of potential concern (COPC) are 
not expected. Depleted uranium was used as ballast within some penetrators but all penetrators were reported as being recovered intact. It is unknown if the penetrator reported lost in a crack on Antelope Lake contained DU or if it was actually lost.

\subsubsection{CAS TA-52-005-TAAL, Joint Test Assembly DU Sites}

The exact location of the Joint Test Assembly (JTA) tests is unknown. Based on available documentation, the apparent target area for the JTA tests is northern half of Antelope Lake. Three DU rings were reported lost on Antelope Lake. Although a large search was conducted for the missing material after the tests, the lost depleted rings were never located. If the DU rings are located on Antelope Lake, they are not located within known radiological control areas and COPC other than DU are not expected.

\subsubsection{Surface Detonation Debris CSM}

This CSM addresses CASs where some type of dispersion test was conducted which resulted in the release of DU, beryllium, and system components to the ground surface (Figure 2 of this appendix). Based on the types of testing activities that resulted in potential contamination at the sites within this CSM, DU, beryllium, and system components will consist of discrete pieces of metal and/or debris on the ground surface. Impacted soil associated with the waste at these sites is assumed to be minimal and only associated with the DU and/or beryllium fragments. Although no subsurface debris is suspected at these sites, the shallow subsurface will be evaluated using geophysical techniques to confirm the CSM. Documentation indicates that cleanup activities were conducted following each of the tests performed at these sites. However, previously completed cleanup of DU at the sites within this CSM has not been verified, and will be evaluated during the planned characterization activities. The following sites are included within the Surface Detonation Debris CSM:

\subsubsection{CAS TA-52-001-TANL, NEDS Detonation Area}

The NEDS tests took place on the northern half of NEDS Lake. However, the exact test location(s) are not known. Based on the documentation, DU and beryllium fragments were recovered at the completion of the NEDS tests. The potential for DU and/or beryllium fragments on the surface of NEDS Lake is possible and will be evaluated during the site investigation. Buried debris is unlikely due to the nature of the tests. The CAS is listed as potential surface contamination due to the DU and/or beryllium that may have been used in the test units. These areas are not located within known radiological control areas, and COPC other than beryllium and/or DU are not expected.

\subsubsection{CAS TA-52-004-TAAL, Metal Particle Dispersion Test}

The location of the MPDT is within a bermed area on the north end of Antelope Lake. Depleted uranium and/or beryllium were used to simulate the dispersal of fissionable radioactive materials. Based on the documentation available, it is unlikely that appreciable amounts of unrecovered DU and/or beryllium fragments remain within the bermed area. The site is described as potential surface contamination area and some amounts of DU and/or beryllium may remain on the surface. Due to the nature of the test and the recovery effort completed as part of the experiment, it is unlikely that any buried debris relating to the MPDT is present. While the bermed area is not formally posted as a radiological area, signs have been placed at the site indicating that the area is a soil contamination area. COPC other than beryllium and/or DU are not expected. 


\subsubsection{CAS TA-52-006-TAPL, Depleted Uranium Site}

The location of the Colimbo Test is marked by a brass at-grade monument on the northern half of NEDS Lake. Documentation indicated that it is unlikely that any large unrecovered fragments remain on the surface. This CAS includes possible surface debris which may be DU and/or beryllium. The area of this CAS is not located within a known radiological control area and COPC other than beryllium and/or DU are not expected.

\subsubsection{Non-Impacted Surface Debris CSM}

This CSM addresses CAS TA-54-001-TANL (Containment Tank and Steel Structure) which consists of non-impacted structures on the ground surface. Figure 3 of this appendix shows this CSM. The structures will be screened to confirm they are not radiologically impacted and the materials will be removed for disposal or recycling.

\subsection{Secondary Conceptual Site Models for CAU 484}

The conditions under the secondary CSMs for CAU 484 are considered less likely than the conditions outlined in the primary CSMs. No information has been identified that suggests conditions outside the primary model are present. The secondary CSMs for CAU 484 are similar to the primary model with one or more of the following exceptions:

\$ Potentially buried debris may be deeper than anticipated. This poses a situation where site conditions may exceed the technical limitations of available geophysical methods.

\$ Surface debris that is expected to be non-impacted is determined to be impacted.

\$ A primary assumption is that DU, if present, will be in discrete pieces and that there will be minimal soil impact. If significant areas of DU-impacted soil are present the CSM will be reevaluated and the investigation-closure strategy may be revised as necessary.

\$ Areas with suspected surface debris are determined to extend into the subsurface.

\$ A CAS can not be located due to unavailability of information, technology limitations, or other causes. Closure of the site will proceed following the precedent established by CAU 495 where the site was promoted to FFACO Appendix IV with the caveat that the site would be reopened for investigation if additional information was found in the future (NDEP, 1999).

\subsection{Potential Hold Points}

During closure activities, certain conditions affecting the project schedule and budget may require decisions prior to continuing work. Primary hold/decision points that may occur during the CAU 484 SAFER process have been identified and include the review of data for the selection of potential site locations for further investigation and the review of analytical data.

The results of geophysical and radiological surveys will be reviewed and presented to the NNSA/NSO and/or the NDEP. Three potential results are possible and will be evaluated for further action. The potential results include the following: a distinct target representing the site will be located, several potential targets will be located, or no potential targets will be identified. If a single target is identified, the data will be reviewed and a decision will be made concerning the type and nature of investigation required. If multiple potential targets are identified, a decision will be made concerning which targets are 
to be investigated and the nature of investigation required. If no targets or potential targets are identified for a specific site the alternative CSM will be evaluated for additional areas of site investigation or closure by no further action using the CAU 495 scenario (caveat that the CAU may be closed but will be reopened if additional information is found in the future) (NDEP, 1999).

An additional hold/decision point occurs during the investigation when results of soil sampling and laboratory analysis for beryllium and DU screening results will be reviewed with the NNSA/NSO and/or the NDEP to confirm the cleanup and/or closure approach. Throughout the investigation/closure process, data will be collected, evaluated, and presented to NNSA/NSO for review and input.

In addition to the previously discussed hold/decision points, work may be temporarily suspended until the issue can be satisfactorily resolved if any of the following unexpected conditions occur:

\$ Conditions outside the scope of work are encountered such as large amounts of unexploded ordinance,

\$ Radiological screening yields results which require an upgrade in procedures to continue survey work in specific areas,

\$ Elevated beryllium levels are found in soil samples,

\$ Elevated levels of additional COPCs are found that were not originally identified as being present at the sites,

\$ Encountering unexpected conditions including waste and/or contamination,

\$ Out-of-scope work activities are required due to the detection of other contaminants of concern (COC) that would require re-evaluating a disposal pathway, such as with hazardous or low level waste,

\$ Unsafe conditions or work practices posing a threat to personnel, equipment, or the environment, not originally documented in the Site Specific Health and Safety Plan, are encountered,

\$ Other technical factors are encountered that require the preparation of a Record of Technical Change to the approved SAFER Plan.

\subsection{IDENTIFY THE DECISION (Step 2)}

Identify what questions the study will attempt to resolve, and what actions may result.

\subsection{Develop Decision Statements}

A SAFER Plan will be prepared based on the currently available process knowledge, historical information, geophysical data, and radiological survey data. The CASs within CAU 484 may be divided into sites where the general location and nature of debris/contamination is known, and sites where the location has not been confirmed and the nature of the debris/contamination is known.

Sites where the general location and nature of debris/contamination are known include the following CASs:

\$ CAS TA-52-001-TANL, NEDS Detonation Area

\$ CAS TA-52-004-TAAL, Metal Particle Dispersion Test

\$ CAS TA-52-006-TAPL, Depleted Uranium Site

\$ CAS RG-52-007-TAML, Davis Gun Penetrator Test (Antelope Tuff Target 1, Antelope Tuff Target 2, Myers Ridge, Sidewinder Tuff Target, Mt. Helen) 
Sites where the location has not been confirmed and the nature of the debris/contamination is known include the following CASs:

\$ CAS TA-52-005-TAAL, Joint Test Assembly DU Sites

$\$$ CAS RG-52-007-TAML, Davis Gun Penetrator Test

(Antelope Lake, Main Lake, Pedro Lake, Brownes Lake, Antelope Tuff, Myers Ridge, Sidewinder Tuff, and Mt. Helen)

For CASs where the location has not been confirmed, historical information, interviews, site conditions, and geophysical and radiological data will be evaluated and a potential target location will be identified for each CAS, if possible. Potential target information will be presented to NNSA/NSO for concurrence. Selected targets will be addressed during the Corrective Action Investigation (CAI). Findings of the CAI will be evaluated with the NNSA/NSO and the corrective action approach will be confirmed and documented. Sites with impacted materials will be either clean closed by removing the impacted material, or closed in place. Clean closure will be verified by conducting a radiological survey for DU, and verification soil samples will be collected if beryllium is identified as a COC.

\subsection{Decision Statements}

Decision I - Is waste present and/or is contamination present above action levels within a CAS? A COPC that is detected at a concentration exceeding action levels will be considered a COC. A COC is defined as a site-related constituent that exceeds the screening criteria or is detected during surface radiological surveys. Depleted uranium will be considered a COC if it is detected during surface surveys.

Decision II - If waste is present and/or contamination is present above action levels or screening levels, has the lateral and vertical extent been determined and is it technically feasible to remove the waste/contamination? (If technically feasible all CASs containing waste/contamination will be clean closed.) If potentially buried debris can not be located the site will be closed using the CAU 495 model (no further action unless additional information is identified in the future) (NDEP, 1999).

\subsection{Alternative Actions to the Decision}

If a COPC is not present, further assessment of that COPC in the CAS is not required. If a COC is present, resolve Decision II. The alternative for Decision II is: "If the extent and migration of a COC is defined in both the lateral and vertical directions, further assessment of the CAS is not required. If the extent of a COC is not defined, reevaluate site conditions and collect additional samples."

Sites with insufficient information and/or data will be evaluated for additional data collection or a "no further action" alternative. If the "no further action" alternative is selected, the approach previously approved by NDEP for CAS 495 (Unconfirmed Joint Test Assembly (JTA) Sites) will be implemented (NDEP, 1999). This approach will allow closure of unconfirmed sites with no land/site use restrictions and no post-closure monitoring. However, should additional evidence become available in the future which indicates the location for the site, the site should be reopened to continue the investigation.

\subsection{IDENTIFY THE INPUTS TO THE DECISION (Step 3)}

Identify the information that needs to be obtained and the measurements that need to be taken to 
resolve the decision statement. This step identifies the information needed and sources of information, the basis for establishing action levels, and sampling and analysis methods that can meet the data requirements.

\subsection{Identify the information inputs needed and resolve the decision.}

In order to confirm the site CSM and to determine the nature and extent of contamination, data must be collected and analyzed following the following three criteria: 1 . Survey data must be collected in areas containing impacted debris and/or contamination; 2. Samples will be collected from areas most likely to be contaminated by beryllium (samples may be analyzed for beryllium and depleted uranium); and 3. The data must be adequate to detect COC. Investigation and closure verification data for DU will be collected using field-screening methods, and beryllium cleanup will be verified through sample collection and analysis. Soil samples may be collected to verify closure activities at depleted uranium-impacted sites.

In order to determine if a COC (e.g., beryllium, depleted uranium) is present at a particular CAS, sample data must be collected and analyzed by two criteria: 1 . Samples must be collected in areas most likely to be contaminated; and 2 . The requested analyses must be sufficient to detect any contamination present within the samples. The only COCs identified for CASs within CAU 484 are DU and beryllium. Depleted uranium characterization will be completed using field survey and screening instruments, and sample collection for laboratory analysis. For sites with beryllium as a COC, the contamination will be associated with DU (due to the nature of the release).

In order to confirm the extent of contamination, data must be collected and analyzed using a data collection method adequate to detect the COC. Samples will be collected based on radiological and geophysical surveys, field observations, and field screening results. Samples will be collected from areas expected not to be impacted by the COC so that the impacted area can be bounded and defined.

Biasing factors to support the determination of the nature and extent criteria include:

\$ Radiological surveys,

$\$$ Geophysical surveys,

\$ Documented process knowledge on source and location of release,

\$ Field observations,

\$ Experience and data from investigations of similar sites,

$\$ \quad$ Professional judgment, and

$\$ \quad$ Field screening results.

\section{Quantitative Data}

Quantitative data measures the quantity or amount of a characteristic or component within the population of interest. These data require the highest level of quality assurance/quality control (QA/QC) in collection and measurement systems because the intended use of the data is to resolve primary decisions, and/or to verify that closure standards have been met. Laboratory analytical data are generally considered quantitative.

\section{Semiquantitative Data}


Semiquantitative data indirectly measure the quantity or amount of a characteristic or component. Inferences are drawn about the quantity or amount of a characteristic or component because a correlation has been shown to exist between the indirect measurement and the results from a quantitative measurement. The QA/QC requirements on semiquantitative collection and measurement systems are high but may not be as rigorous as a quantitative measurement system. Semiquantitative data contribute to decision making but are not sued alone to resolve primary decisions. Field-screening data are generally considered semiquantitative. The data are often used to guide investigations toward quantitative data collection.

\section{Qualitative Data}

Qualitative data identify or describe the characteristics or components of the population of interest. The $\mathrm{QA} / \mathrm{QC}$ requirements are the least rigorous on data collection methods and measurement systems. The intended use of the data is for information purposes, to refine conceptual models, and to guide investigations rather than resolve primary decisions. This measurement of quality is typically assigned to historical information and data where QA/QC may be highly variable or not known. Professional judgment is often used to generate qualitative data.

\section{Hold Points}

Hold points will be designed into the investigation and closure activities for CAU 484. Hold points are designed to allow decision makers to review the existing data and decide which of the available options are most suitable. Hold points include the review of geophysical and radiological data and field observations for selection of targets for investigation, selection of corrective actions. The major hold points for this project have been identified and are discussed in Section 1.4

\subsection{List Types of Contaminants of Potential Concern and Affected Media}

It is expected that DU and beryllium fragments may be found at several locations on the dry lake surfaces (Surface Detonation Debris CSM). The most likely locations where these materials may be found are within the following CASs:

\$ TA-52-001-TANL, NEDS Detonation Area

\$ TA-52-004-TAAL, Metal Particle Dispersion Test

\$ TA-52-006-TAPL, Depleted Uranium Site

Depleted uranium and/or inert debris may be found on the surface and/or shallow subsurface at several locations on the dry lake and other testing locations on the TTR (Surface-Shallow Subsurface Debris CSM). The most likely locations where these materials may be found are within the following CASs:

- RG-52-007-TAML, Davis Gun Penetrator Test

- $\quad$ TA-52-005-TAAL, Joint Test Assembly DU Sites

\subsection{Identify Potential Sampling Approaches and Appropriate Analytical Methods}

The sampling techniques and analytical methods identified below will be used to resolve the decision rules and confirm the nature and extent of contamination at each CAS.

\section{Geophysical Surveys}

Electromagnetic surveys will be used to determine the presence and lateral extent of areas containing surface or near-surface metallic objects/debris. Geophysical surveys followed standard procedures for 
the instrumentation used. The initial geophysical method used to survey CAS locations will be surveys with a metal detector, however additional geophysical methods may be used as needed to better refine the CAS boundaries and/or locations.

\section{Radiological Survey}

Radiological surveys will be used to determine the presence and lateral extent of radiological contamination. The initial survey will be completed using a truck mounted gamma ray spectrometer system reporting, as a minimum, gross counts for meta-stable Protactinium-234. Additional radiological survey methods may be used as needed to complete the corrective action investigation. Data will be collected and reduced daily in order to provide data in near real-time for QA and survey operational decisions. The initial survey will be conducted at an instrument height of 71 centimeters ( 28 inches) above the ground surface with an expected sensitivity of 10 milliCuries (approximately 30 grams or 1.5 cubic centimeters of DU). The instrument height may be lowered to approximately 35.5 centimeters (14 inches) above the ground surface for an expected sensitivity of 1 milliCurie (approximately 3 grams or 0.15 cubic centimeters of DU).

\section{Radiological Field Screening}

Based on site conditions and available data, field-screening activities may be conducted for alpha and beta/gamma radiation. A handheld radiological survey instrument or method may be used, based on the possibility that radiologically contaminated soil/debris may be present. If determined appropriate, onsite gamma spectrometry may also be used to screen samples.

Field screening techniques may be used during the Decision I and II sampling activities. These fieldscreening techniques will provide semiquantitative data that can be used to guide potential confirmatory sampling and waste management activities.

\section{Soil Sampling}

Hand sampling, auguring, direct push, excavation, drilling, or other appropriate sampling methods may be used to collect soil samples. Sample collection and handling activities will only be conducted in accordance with approved procedures. Soil samples will be collected (from CASs within the Surface Detonation Debris CSM) from biased and random locations after potential target areas have been determine from the geophysical and radiological survey data.

\subsection{DEFINE THE STUDY BOUNDARIES (Step 4)}

Specify the time periods and spatial area to which decisions will apply. Determine when and where data should be collected. The purpose of this step is to define the target population of interest, specify the spatial and temporal features of that population that are pertinent for decision making, determine practical constraints on data collection, and define the scale of decision making relevant to target populations for Decision I and Decision II.

\subsection{Define the Geographic Areas of the Field Investigation.}




\subsubsection{Define the Geographic Area Within Which all Decisions Must Apply}

CAU 484 has been defined based on the historical data collected during previous investigations. The area of the surveys will include Brownes Lake, Pedro Lake, the northern half of Antelope Lake, and the northern half of NEDS Lake. Former test locations at Myers Ridge, Sidewinder Tuff, and Mt. Helen are also included in CAU 484.

\subsubsection{Specify the Characteristics that Define the Population of Interest}

The population of interest is all of the survey areas. The debris may include material found on the surface or buried near-surface, as identified by geophysical and radiological methods and/or visual inspection of the survey area.

\subsection{Define the Time Frame of the Decision}

\subsubsection{Determine the Time Frame to Which the Study Data Apply}

The study data should be relevant with the length of time allowed for by the SAFER process under the FFACO agreement. The decisions will be based on the documentation and data collection activities planned for 2004 and combined with the planned surveys to determine the proper recommendations for each of the CASs.

\subsubsection{Determine When to Collect Data}

Data collection activities are scheduled to begin in fiscal year 2004 and closure activities will be completed after approval of the final SAFER Plan. Data will be collected at times that meet the security and safety constraints of the TTR site, and at times when weather conditions that allow adequate site access and safe working conditions. A tentative schedule of activities for the completion of CAU 484 is presented in the SAFER Plan.

Radiological screening will be used to detect radiation above free-release criteria before any debris is removed off-site. There will be no other data collection, unless staining or other evidence of the presence of COPC or potential environmental impact is visibly detected and is determined to be related to CAU 484.

\subsubsection{Define Relevant Time Constraints}

\$ The final SAFER Plan is due to the U.S. Department of Energy, National Nuclear Security Administration Nevada Site Office by May 10, 2004.

\$ The FFACO deadline for the SAFER Plan is September 30, 2004.

\$ Fieldwork will be tentatively scheduled to begin during fiscal year 2005.

\subsection{Identify Any Practical Constraints on Data Collection}

1. Approval of the SAFER Plan and the DQO process by the NDEP.

2 Equipment access and mobility at the TTR.

3. Meteorological events that may impact fieldwork activities.

4. Health and safety of workers.

5. Operational/Security issues at the TTR. 
6. Unforeseen conditions including unexploded ordnance and other unsafe working conditions.

\subsection{DEVELOP A DECISION RULE (Step 5)}

Define the parameter of interest, specify the action level, and integrate the previous DQO inputs into a single statement that describes the logical basis for choosing among alternative actions. This step integrates outputs from the previous steps, with the inputs developed in this step into a decision rule ('If..., then...") statement. This decision rule describes the conditions under which possible alternative actions would be chosen.

\subsection{Decision Rule}

Decision I - If waste is present and/or contamination is present above action levels, then the horizontal and vertical extent will be determined.

Decision II - If waste or contamination is present above action levels, and it is technically feasible to clean close the site, then the site will be clean closed.

If contamination is inconsistent with the CSM or extends beyond the identified CAS boundaries, work will be suspended and the investigation strategy will be reevaluated. If contamination is consistent with the CSM and is within CAS boundaries, the decision will be to define its extent.

\subsection{Specify the Action Level or Preliminary Action Level for the Decision}

Sufficient process knowledge and site surveys exist to support the CSMs. Beryllium and DU are the only COPCs within CAU 484. The most recently approved preliminary remediation goal (PRG) for industrial soils will be used as the action level for beryllium (EPA, 2002). As any DU detected at the sites will likely be in the form of discrete pieces, a hot-spot cleanup approach will be used. Depleted uranium pieces detected during the surveys will be removed as localized hot-spots from which the DU and the soil immediately surrounding it will be removed for disposal. Closure will be verified using field survey methods. An approach similar to that used to characterize, remove, and verify cleanup of DU at CAU 425 will be utilized at CAU 484 (NNSA/NSO, 2003). Soil samples may be collected to confirm depleted uranium concentrations and to verify closure activities. Depleted uranium analytical results will be compared to the recently approved action level of 60 picoCuries per gram which is based on a 15 mrem per year dose limit described in Nation Council on Radiation Protection report number 129 (NCRP 1999).

\subsection{SPECIFY TOLERABLE LIMITS ON DECISION ERRORS (Step 6)}

Define the decision makers' tolerable decision error rates based on a consideration of the consequences of making an incorrect decision.

\subsection{Decision Errors}

False Negative (Rejection) Decision Error (Is waste/contamination determined not to be present when it actually is present?)

False Positive Decision Error (Is waste/contamination determined to be present when it is actually not present?) 


\subsection{COPC Models}

Models have been developed to characterize the COPCs for CASs within CAU 484. The models contain assumptions and statistical methodologies as appropriate to achieve the investigation/closure objectives. Table 1 summarizes the COPCs expected at CAU 484.

TABLE 1 - CAU 484 WASTE AND COPC DESCRIPTION

\begin{tabular}{|c|c|c|c|c|c|}
\hline \multirow{2}{*}{ CAS } & \multirow{2}{*}{$\begin{array}{c}\text { CAS } \\
\text { Description }\end{array}$} & \multicolumn{2}{|c|}{$\begin{array}{c}\text { Contaminants of } \\
\text { Potential Concern } \\
\end{array}$} & \multirow{2}{*}{$\begin{array}{c}\text { Impacted/Non- } \\
\text { Impacted } \\
\text { Debris }\end{array}$} & \multirow{2}{*}{$\begin{array}{c}\text { Contaminant/Waste } \\
\text { Description }\end{array}$} \\
\hline & & \begin{tabular}{|c|} 
Depleted \\
Uranium \\
\end{tabular} & Beryllium & & \\
\hline $\begin{array}{l}\text { RG-52-007- } \\
\text { TAML }\end{array}$ & $\begin{array}{c}\text { Davis Gun } \\
\text { Penetrator Test }\end{array}$ & Unknown & N/A & Unknown & $\begin{array}{l}\text { DU/inert debris on the } \\
\text { ground surface or shallow } \\
\text { subsurface }\end{array}$ \\
\hline $\begin{array}{l}\text { TA-52-001- } \\
\text { TANL }\end{array}$ & $\begin{array}{c}\text { NEDS } \\
\text { Detonation Area }\end{array}$ & Yes & Yes & N/A & $\begin{array}{l}\text { DU and beryllium } \\
\text { dispersed on the ground } \\
\text { surface }\end{array}$ \\
\hline $\begin{array}{l}\text { TA-52-004- } \\
\text { TAAL }\end{array}$ & $\begin{array}{c}\text { Metal Particle } \\
\text { Dispersion Test }\end{array}$ & Yes & Yes & N/A & $\begin{array}{l}\text { DU and beryllium } \\
\text { dispersed on the ground } \\
\text { surface }\end{array}$ \\
\hline $\begin{array}{l}\text { Ta-52-005- } \\
\text { TAAL }\end{array}$ & $\begin{array}{c}\text { Joint Test } \\
\text { Assembly DU } \\
\text { Sites } \\
\end{array}$ & Yes & N/A & N/A & $\begin{array}{l}\text { DU rings on the ground } \\
\text { surface or shallow } \\
\text { subsurface }\end{array}$ \\
\hline $\begin{array}{l}\text { TA-52-006- } \\
\text { TAPL }\end{array}$ & $\begin{array}{c}\text { Depleted } \\
\text { Uranium Site } \\
(\text { Colimbo })\end{array}$ & Yes & Yes & Unknown* & $\begin{array}{l}\text { DU and beryllium } \\
\text { dispersed on the ground } \\
\text { surface } \\
* \text { An unconfirmed sealed } \\
\text { cobalt radiological source } \\
\text { may be present at the site }\end{array}$ \\
\hline $\begin{array}{l}\text { TA-54-001- } \\
\text { TANL }\end{array}$ & $\begin{array}{c}\text { Tank and Steel } \\
\text { Structure } \\
\end{array}$ & N/A & N/A & Yes & $\begin{array}{l}\text { Debris on the ground } \\
\text { surface }\end{array}$ \\
\hline
\end{tabular}

\subsubsection{Beryllium Statistical Model}

Statistical model applies to potential beryllium contamination within the Surface Detonation Debris CSM sites. The EPA document Guidance for Choosing a Sampling Design for Environmental Data Collection (EPA, 2000a) defines the methodology suggested to determine the sufficient number of samples to be collected to ensure a 95 percent confidence level in the COPC concentration. This methodology has been used to determine the number of sampling locations required at sites potentially impacted by beryllium in CAU 484. The number of samples required may be determined using the following equation:

$\mathrm{n}=\mathrm{ta}_{\mathrm{a}}{ }^{2}(\mathrm{CV})^{2} / \mathrm{p}^{2}$ 
Where:

$\mathrm{n} \quad=$ number of samples

$\mathrm{t}_{\mathrm{a}} \quad=$ statistical factor for a $95 \%$ confidence level

$\mathrm{CV}=$ coefficient of variation

$\mathrm{p} \quad=$ margin of error

As the $\mathrm{CV}$ increases at a set margin of error, the number of samples required increases. When the variability is low relative to the mean of the data, the $\mathrm{CV}$ is also low. However, as the variability in the population begins to increase relative to the mean of the data, the $\mathrm{CV}$ will increase and the number of required samples will increase if characterization of the site at a $95 \%$ confidence level and a set margin of error is desired. The value of $\mathrm{ta}^{2}$ increases as the number of samples decreases. Therefore, $\operatorname{ta} 2$ is inversely proportional to the number of samples collected. The minimum number of samples required to ensure a 95-percent confidence level is also directly proportional to the coefficient of variation (CV) in the concentration of the COPCs. The CV is a quantification of the amount of internal fluctuation in the concentration from sample to sample. It is an absolute measure of the amount of internal variation in the concentration data and does not, to a first approximation, depend on the number of samples collected. The margin of error may be obtained by dividing the precision wanted by the known or anticipated mean concentration of the specific COPC. Upon completion of the soil sampling effort, the data obtained for the COCs is reviewed. It can then be determined if an adequate number of samples were collected with respect to the margin of error and confidence selected during the planning process. This determination is completed by calculating the $\mathrm{CV}$ using the data obtained during the study. The standard deviation of the concentration for a COC is divided by the mean concentration to calculate the $\mathrm{CV}$. This $\mathrm{CV}$ may be higher or lower than the $\mathrm{CV}$ selected during the planning process. Using this $\mathrm{CV}$ value, the same equation is used to determine the required number of samples based on the actual $\mathrm{CV}$ for the study. If this second value for " $n$ " is less than or equal to the number of samples collected during the study, then the site has been characterized for extent of COCs within the limits of confidence and error stated. If the second value for " $n$ " is significantly greater, then additional sampling is necessary, or an adjustment to the margin of error or confidence level should be considered. If the collection of additional samples is deemed necessary, the data that has been generated may be used to plan for a more efficient and cost-effective re-sampling of the site. Areas of the site where higher than anticipated variabilities were obtained may be segregated from areas of lower variability (stratified design). A recalculation of the number of samples required to characterize each strata should then be completed and resampling may proceed.

Beryllium and isotopic uranium analytical data collected from CAU 529 (Area 25 Contaminated Materials) CAS 25-23-17 (Contaminated Wash) will be used to calculate an estimate of the number of samples needed for CAU 484. Soil samples for beryllium and DU analysis will be collected concurrently; therefore, the most conservative CV within the CAU 529 beryllium and DU data will be used to estimate the number of samples to be collected at the Surface Detonation Debris Sites in CAU 484. CAU 529 has been selected because contamination at this site was the result of a detonation of a test article containing similar material to that used during testing activities at the Surface Detonation Debris sites within CAU 484. Analytical data from samples collected at CAU 484 sites will be 
statistically analyzed and evaluated to confirm a sufficient number of samples have been collected and data meets project objectives.

Due to the nature of the event (detonation of a test article from a point source) beryllium concentrations are assumed to be normally distributed on the ground surface with the greatest concentration occurring at and near the point source and decreasing in all directions away from the point source. The sampling plan will include a combination of biased and random sample locations. Random sample locations will be selected using a grid and a random number generator. Surface and shallow subsurface soil samples will be collected to document the lateral and vertical extent of beryllium contamination. If beryllium is detected above the PRG in any sample, step-out sample locations will be established and additional samples will be collected for laboratory analysis.

\subsubsection{Depleted Uranium Model}

The DU model applies to sites within the Surface Detonation Debris and Surface-Shallow Subsurface Debris CSMs. Antelope, Brownes, Pedro and NEDS Lake beds will be surveyed using geophysical and radiological equipment with a coverage exceeding 90 percent of the study area.

\subsubsection{Surface Detonation Debris}

Due to the nature of the event (detonation of a test article from a point source) DU debris is assumed to be normally distributed as discrete pieces on the ground surface, with the greatest concentration occurring at and near the point source of detonation and decreasing in all directions away from the point source. Conditions similar to those encountered at CAU 529 CAS 25-23-17 (Contaminated Wash) are expected at sites within the surface detonation debris CSM. The source of contamination is similar in that events at all locations are related to the detonation of a test article containing uranium and beryllium. Uranium detected during the investigation of CAU 529 CAS 25-23-17 (Contaminated Wash) consisted of discrete pieces as is expected at the sites within CAU 484. Locations containing DU within this CSM will be identified and verified using field survey methods. While field screening will be the primary tool for confirming removal of depleted uranium, soil samples may be collected to verify depleted uranium concentrations and closure objectives. Soil sampling will be based on the methods described for the beryllium statistical model. Cleanup of DU will be based on the approach discussed in Section 5.2.

\subsubsection{Surface-Shallow Subsurface Debris}

Depleted uranium at sites within this CSM may contain debris and/or intact test articles on the ground surface or shallow subsurface. Depleted uranium present at these sites is assumed to consist of discrete pieces and may only have impacted the soil/media in contact with the DU. Locations containing DU within this CSM will be identified and verified using field survey methods. Cleanup will be based on the approach discussed in section 5.2.

\subsection{Confirmation of Corrective Actions}

Sites selected for clean closure will require the collection of data to support and verify that corrective actions are complete. Beryllium analytical data collected during the CAI will be used as input to the equation presented in Section 6.2.1 to determine the minimum number of samples required to verify the 
closure objectives. Beryllium verification sample results will be compared to the most current PRG at the time of the cleanup. As any DU detected is assumed to be discrete pieces, the pieces and associated soil will be removed and clean closure of sites impacted with DU will be verified using fieldsurvey methods (similar to DU cleanup completed at CAU 425 [NNSA/NSO, 2003]).

\subsection{OPTIMIZE THE DESIGN (Step 7)}

Evaluate information from the previous steps and generate alternative data collection designs. Choose the most resource-effective design that meets all DQOs. This section presents an overview of the resource-effective strategy planned to obtain the data required to meet the project DQOs developed in previous steps. As additional data or information is obtained, this step will be reevaluated and refined, if necessary, to reduce uncertainty and increase the confidence that the SAFER CAI has met its intended goals.

\subsection{Develop General Sampling and Analysis Design Alternatives}

Assumptions for the beryllium statistical model are presented in Section 6.2.1. Data collected during the investigation of a similar corrective action site will be used to make an estimation of the number of samples that need to be collected at sites within the surface detonation debris conceptual site model. This is necessary since no analytical data are available from the sites within CAU 484 on which to make a determination. After the CAU 484 CAI is complete, the beryllium and/or depleted uranium data will be analyzed to confirm that sufficient samples were collected to characterize the site at the 95-percent confidence level.

A combination of biased and random samples will be collected to verify the horizontal and vertical extent of potential beryllium contamination for sites within the Surface Detonation Debris CSM. One sample will be collected from the central area of the detonation and one sample will be collected from four locations some distance from the central area of the detonation. Additional random samples will be collected as indicated by the output from the equation presented in section 6.2.1. Additional samples may be collected as needed to fill data gaps and to provide data needed to complete the investigation/closure.

Areas on the dry lake beds containing DU will be initially surveyed with a coverage exceeding 90 percent using the Kiwi equipment. This phase of the CAI will be to confirm the locations of CASs within the CAU. Sites identified during this phase to be associated with CAU 484 will be further investigated using field screening methodologies.

\subsection{CAU 484 Closure Decision Process}

Hold/decision points have been included in the process to allow critical data to be reviewed by the parties prior to proceeding with the closure activities. A primary hold point for the CAU 484 closure activities will be the review of geophysical and radiological survey data and the selection of locations representing sites belonging to CAU 484. Due to the broadness of the initial surveys and the historical activities that have been conducted on the dry lake beds at TTR, there is a potential for identifying sites containing waste and/or contamination that are not associated with CAU 484. Only sites determined to be associated with CAU 484 will be addressed within the corrective actions described in these data quality objectives. 


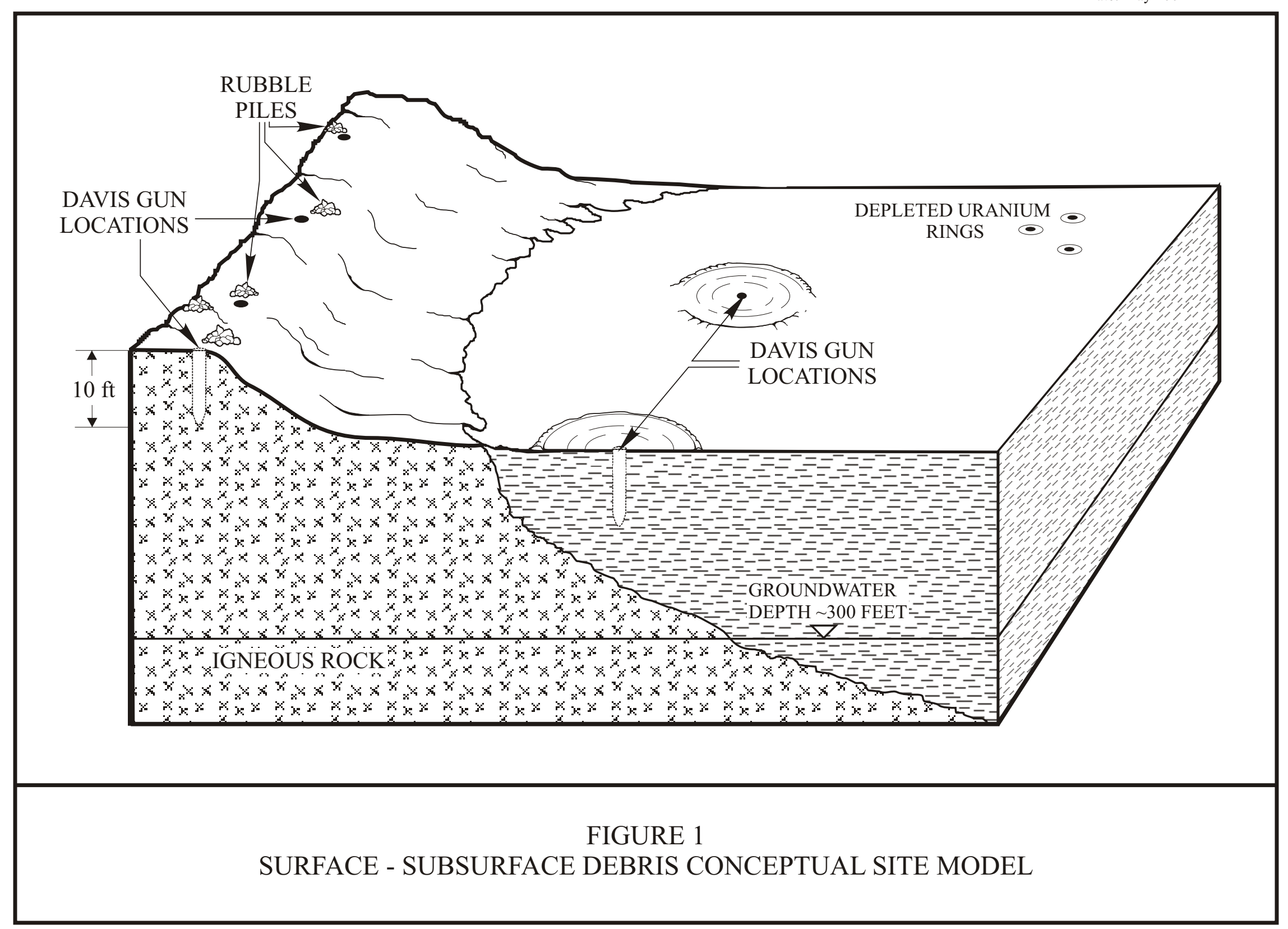




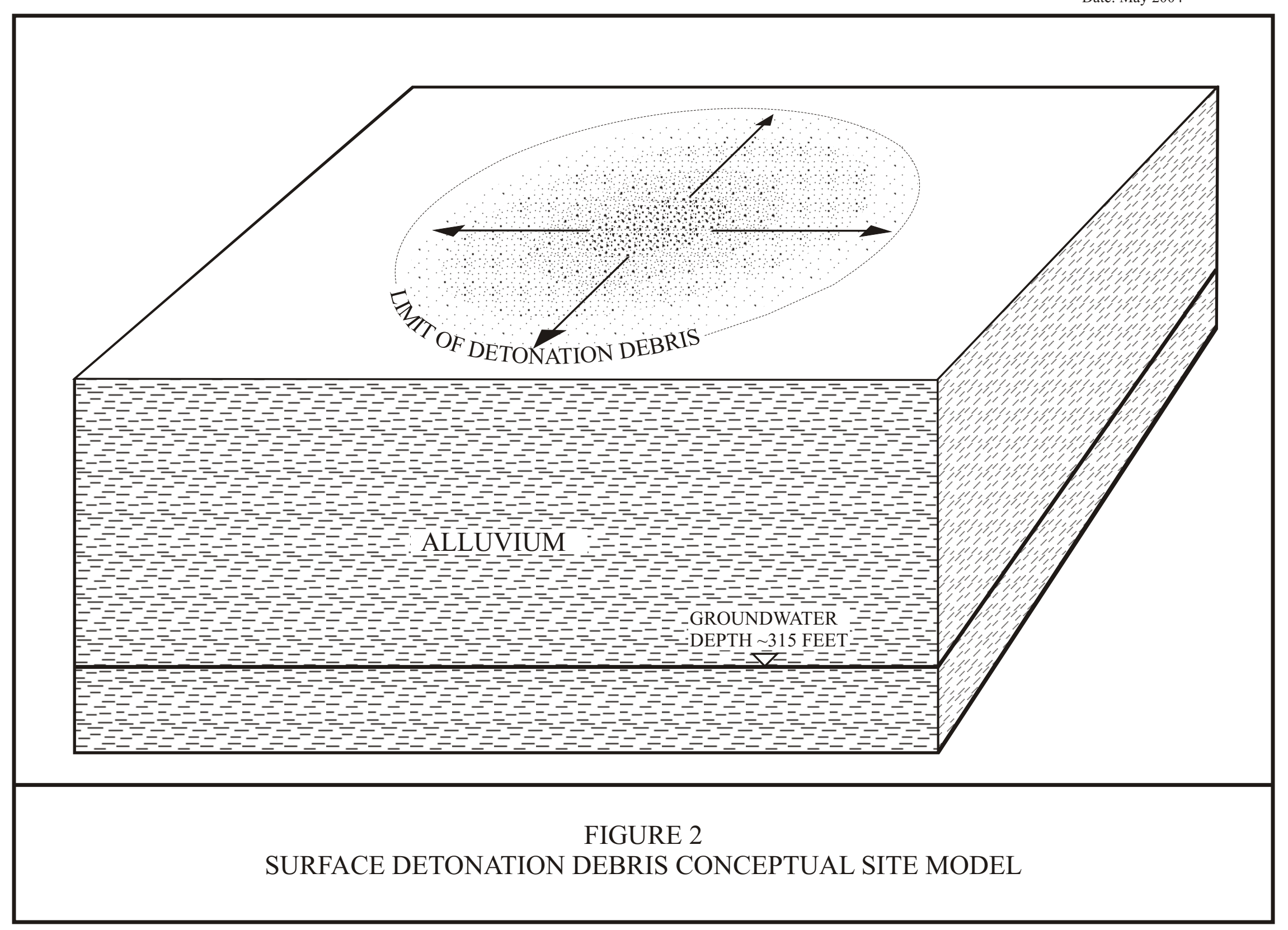




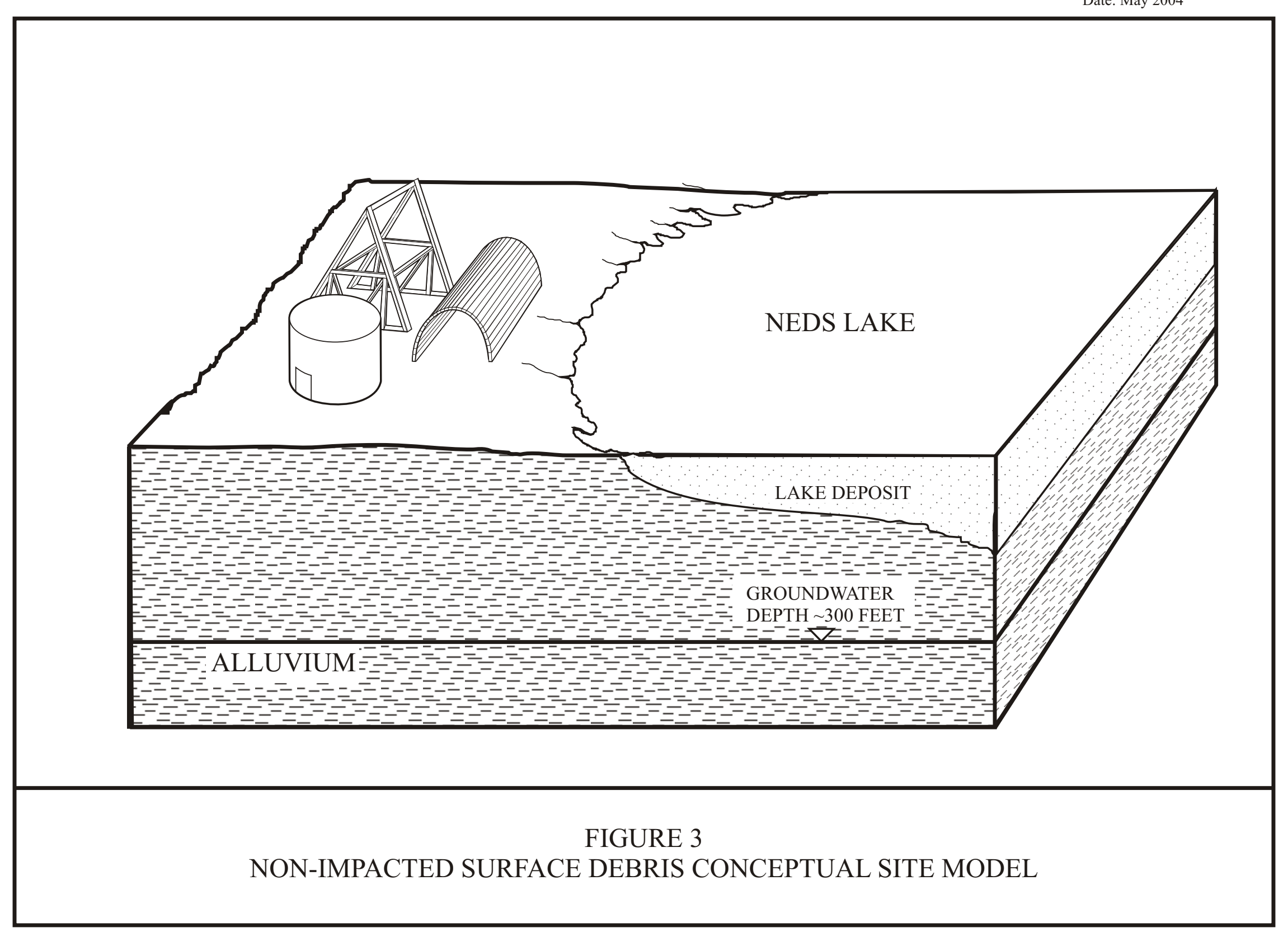




\section{REFERENCES}

EPA, see U.S. Environmental Protection Agency.

NCRP, see National Council on Radiation Protection and Measurements.

NDEP, see Nevada Division of Environmental Protection.

NNSA/NSO, see U.S. Department of Energy, National Nuclear Security Administration Nevada Site Office

National Council on Radiation Protection and Measurements. 1999. Recommended Screening Limits for contaminated Surface Soil and Review of Factors Relevant to Site-Specific Studies. NCRP Report No. 129. National Council on Radiation Protection and Measurement, Bethesda, MD.

Nevada Division of Environmental Protection. 1999. Letter to Runore Wycoff, U.S. Department of Energy Nevada Operations Office. Notice of Completion for Corrective Action Unit 495, Unconfirmed Joint Test Assembly (JTA) Sites, TTR. July 14. Carson City, NV.

U.S. Department of Energy, National Nuclear Security Administration Nevada Site Office. 2003. Closure Report for Corrective Action Unit 425: Area 9 Main Lake Construction Debris Disposal Area, Tonopah Test Range, Nevada, DOE/NV--875. Las Vegas, NV.

U.S. Environmental Protection Agency. 2000a. Guidance for Choosing a Sampling Design for Environmental Data Collection (EPA QA/G-5), Office of Environmental Information, Washington, D.C.

U.S. Environmental Protection Agency. 2000b. Guidance for the Data Quality Objective Process, EPA QA/G-4, Washington, D.C.

U.S. Environmental Protection Agency. 2002. Region IX Preliminary Remediation Goals (PRGs), San Francisco, CA. 
SAFER PLAN - CAU 484

Section: Appendix A1

Revision: 0

Date: May 2004

THIS PAGE INTENTIONALLY LEFT BLANK 
SAFER PLAN - CAU 484

Section: Appendix A2

Revision: 0

Date: May 2004

\section{APPENDIX A2}

\section{PROJECT ORGANIZATION}


SAFER PLAN - CAU 484

Section: Appendix A2

Revision: 0

Date: May 2004

THIS PAGE INTENTIONALLY LEFT BLANK 


\section{PROJECT ORGANIZATION}

The U.S. Department of Energy, National Nuclear Security Administration Nevada Site Office (NNSA/NSO) Project Manager or Task Manager will serve as the primary point of contact for all activities conducted in this project. The NNSA/NSO Project Manager is responsible for seeing that all activities conducted during the project fulfill the obligations of NNSA/NSO as described in the Federal Facility Agreement and Consent Order (FFACO) of 1996 and the Nevada Division of Environmental Protection (NDEP) approved work plan. The NNSA/NSO Project Manager will plan, authorize, and control project work so that activities are completed in accordance with the work plan on schedule and within budget. The NNSA/NSO Project Manager will be the primary point of contact with the NDEP. The NNSA/NSO points of contact for this project are as follows:

Acting Director: Monica Sanchez

Telephone Number: (702) 295-0160

Project Manager: Janet Appenzeller-Wing

Telephone Number. (702) 295-0461

The identification of the project Health and Safety Officer and the Quality Assurance Officer can be found in both the Field Management Plan and the Site-Specific Health and Safety Plan. However, personnel are subject to change and it is suggested that the appropriate NNSA/NSO Project Manager be contacted for further information. The Task Manager will be identified in the FFACO Monthly Activity Report prior to the start of field activities. 
SAFER PLAN - CAU 484

Section: Appendix A2

Revision: 0

Date: May 2004

THIS PAGE INTENTIONALLY LEFT BLANK 
SAFER PLAN - CAU 484

Section: Distribution List

Revision: 0

Date: May 2004

\section{DISTRIBUTION LIST}


SAFER PLAN - CAU 484

Section: Distribution List

Revision: 0

Date: May 2004

THIS PAGE INTENTIONALLY LEFT BLANK 


\section{DRAFT DISTRIBUTION LIST}

*Distribute only NDEP-approved revisions; others receive all revisions.

\section{Nevada Department of Environmental Protection}

Ms. Terre A. Maize, Chief

1 (Controlled)

Bureau of Federal Facilities

Division of Environmental Protection

1771 East Flamingo Road, Suite 121-A

Las Vegas, NV 89119-0837

Bureau of Federal Facilities

1 (Controlled)

Division of Environmental Protection

333 W. Nye Lane, Room 138

Carson City, NV 89706-0851

Donald Elle

1 (Controlled)

Bureau of Federal Facilities

Division of Environmental Protection

1771 East Flamingo Road, Suite 121-A

Las Vegas, NV 89119-0837

\section{U.S. Department of Energy}

Shirley Doty

1 (Controlled)

Environmental Restoration Division

U.S. Department of Energy

National Nuclear Security Administration Nevada Site Office

P.O. Box 98518, M/S 505

Las Vegas, NV 89193-8518

Kevin Cabble

1 (Uncontrolled)

Environmental Restoration Division

U.S. Department of Energy

National Nuclear Security Administration Nevada Site Office

P.O. Box 98518, M/S 505

Las Vegas, NV 89193-8518

Janet Appenzeller-Wing

1 (Uncontrolled)

Environmental Restoration Division

U.S. Department of Energy

National Nuclear Security Administration Nevada Site Office

P.O. Box 98518, M/S 505

Las Vegas, NV 89193-8518 


\section{DISTRIBUTION LIST (continued)}

*Distribute only NDEP-approved revisions; others receive all revisions.

\section{U.S. Department of Energy (continued)}

Southern Nevada Public Reading Facility

c/o Nuclear Testing Archive

P.O. Box 98521, M/S 400

Las Vegas, NV 89193-8521

U.S. Department of Energy

National Nuclear Security Administration Nevada Site Office

Technical Library

P.O. Box 98518, M/S 505

Las Vegas, NV 89193-8518

U.S. Department of Energy

Office of Scientific and Technical Information

P.O. Box 62

Oak Ridge, TN 37831-0062

\section{$\underline{\text { Bechtel Nevada }}$}

Correspondence Control

Bechtel Nevada

P.O. Box 98521, M/S NLV008

Las Vegas, NV 89193-8521

Kevin Campbell

Bechtel Nevada

P.O. Box 98521, M/S NTS306

Las Vegas, NV 89193-8521

Brad Jackson

Bechtel Nevada

P.O. Box 98521, M/S NTS306

Las Vegas, NV

David Madsen

Bechtel Nevada

P.O. Box 98521, M/S NTS306

Las Vegas, NV 89193-8521
1 (Controlled)* \&

1 (Uncontrolled)*

1 (Uncontrolled)* 


\section{DISTRIBUTION LIST (continued)}

*Distribute only NDEP-approved revisions; others receive all revisions.

\section{$\underline{\text { Nye County }}$}

David Swanson

1 (Uncontrolled) \&

Assistant Project Administrator

1 (Uncontrolled Electronic)*

Nye County

Department of Natural Resources and Federal Facilities

1210 E. Basin Road, Suite 6

Pahrump, NV 89060

\section{$\underline{\text { Stoller-Navarro Joint Venture }}$}

Public Reading Room Coordinator

1 (Controlled)*

Stoller-Navarro Joint Venture

7710 W. Cheyenne Ave., Bldg. 3

Las Vegas, NV 89129

Brian Hoenes

1 (Uncontrolled)

Stoller-Navarro Joint Venture

7710 W. Cheyenne Ave., Bldg. 3

Las Vegas, NV 89129

\section{State of Nevada}

Manager, Northern Nevada FFACO

1 (Uncontrolled)*

Public Reading Facility

c/o Nevada State Library and Archives

100 North Stewart Street

Carson City, NV 89701-4285

\section{$\underline{\text { U.S. Air Force }}$}

E. V. Hopper

3 (Uncontrolled)

U.S. Air Force

99ABW-EM

4349 Duffer Drive, Suite 1601

Nellis AFB, NV 89191-7007

U.S. Air Force

1 (Uncontrolled)

98th Range Wing, XPL

Nellis AFB, NV 89191-7007 


\section{DISTRIBUTION LIST (continued)}

*Distribute only NDEP-approved revisions; others receive all revisions.

$\underline{\text { U.S. Air Force (continued) }}$

U.S. Air Force

1 (Uncontrolled)

DOE Liaison Office

P.O. Box 98518, M/S 505

Las Vegas, NV 89193-8518

\section{$\underline{\text { Sandia National Laboratories }}$}

V. G. Gabbard

1 (Uncontrolled)

Sandia National Laboratory/TTR

Box 871

Tonopah, NV 89049

Jerry Elliston

1 (Uncontrolled)

Westinghouse

P.O. Box 528

Tonopah, NV 89049 